\title{
JOSÉ LUIS ROMERO Y LA HISTORIA DEL SIGLO XXI*
}

\author{
Carlos Barros \\ Universidad de Santiago de Compostela
}

\begin{abstract}
Resumo
Análisis de la obra de un historiador argentino poco conocido. José Luis Romero se mueve entre Annales y el marxismo de manera independiente, es creativo y global: el único que hace "historia total", según Jacques Le Goff. Medievalista y contemporaneísta. Cultiva la historia europea, argentina y latinoamericana. Trabajador empírico y teórico. Hombre académico y hombre de acción (socialista democrático). Se anticipó a su tiempo desde la "periferia" latina y es un precursor de Historia a Debate, tendencia historiográfica del siglo XXI.

Pallavras-chave

historiografía América Latina $\bullet$ Annales y marxismo $\bullet$ metodología medieval $\bullet$ historia total $\bullet$ historia argentina
\end{abstract}

\author{
Contato \\ Departamento de Historia Medieval y Moderna \\ Facultad de Geografía e Historia \\ Plaza de la Universidad, 1 \\ 15782 - Santiago de Compostela - España \\ E-mail: carlos.barros@usc.es, cbarros@wanadoo.es \\ www.cbarros.com, www.h-debate.com
}

\footnotetext{
* Versión escrita, revisada, anotada y ampliada por el autor de la conferencia dictada el 1 de abril de 2009 en el Auditorio Jorge Luis Borges de la Biblioteca Nacional de Argentina, durante las Jornadas Internacionales "José Luis Romero", organizadas por la Universidad Nacional de San Martín en Buenos Aires.
} 


\title{
JOSÉ LUIS ROMERO \\ AND XXI CENTURY'S HISTORY
}

Carlos Barros

Universidad de Santiago de Compostela

\section{Abstract}

Analysis of the work of a little-known argentine historian. José Luis Romero moves independently, creatively and globally between Marxism and Annales: the only thing that makes "total history", as Jacques Le Goff. Medievalist and contemporaryist. Cultivates European history, Argentine history and Latin American history. Empirical and theoretical worker. Academician and man of action (democratic socialist). Was a head of his time from the "periphery" Latin and was a precursor of History under Debate.

\section{Keywords}

Latin American historiography $\bullet$ Annales and marxism $\bullet$ medieval methodology $\bullet$ total history $\bullet$ Argentine history

\author{
Contact \\ Departamento de Historia Medieval y Moderna \\ Facultad de Geografía y Historia \\ Plaza de la Universidad, 1 \\ 15782 - Santiago de Compostela - España \\ E-mail: carlos.barros@usc.es, cbarros@wanadoo.es \\ www.cbarros.com, www.h-debate.com
}




\section{Carlos BARROS. José Luis Romero y la Historia del siglo XXI.}

El objetivo final de ese artículo es debatir la importancia internacional de la vida y obra del historiador argentino José Luis Romero para hacer frente a los retos del presente: caída de las grandes escuelas del siglo XX (Annales, Past and Present) y nuevas realidades históricas e historiográficas del siglo XXI, marcado por globalizaciones de distinto signo. Todo ello sin retornar al viejo positivismo ni renunciar al "oficio", como piden los posmodernos genuinos. Lo que exige pensar por nosotros mismos, aceptando como dijo Peter Burke en el I Congreso Internacional Historia a Debate (1993) que la renovación ahora va por la periferia': el mejor ejemplo es José Luis Romero y sus "pensamientos anticipatorios".

Primeramente ubicaremos a José Luis Romero en la historiografía del siglo $\mathrm{XX}$, haciendo hincapié en una excepcionalidad que explica que su obra histórica - y política - haya resistido mejor que otras aportaciones coetáneas de tipo individual, de ámbito nacional o internacional, al paso del tiempo.

Formado en el periodo de entreguerras, hegemonizado historiográficamente por el positivismo, buscó siempre nutrientes intelectuales menos estrechos, más diversos, en detrimento de una cómoda y segura carrera académica. ${ }^{3}$ Declara Romero, un año antes de morir (1977, con 68 años), en ese magnífico testamento, historiográfico y vital, ${ }^{4}$ que son las conversaciones con Félix Luna: "Como usted se imaginará, yo nunca me he sentido muy cómodo entre mis colegas, porque, por mi formación, nunca he tenido la vocación de ser un documentalista. Y como era la única historia admitida, la única manera admitida de hacer historia, yo siempre me he sentido un poco marginado". ${ }^{5}$ Aunque está hablando, concretamente, de cuándo y porqué organizó su revista crítica Imago Mundi, ${ }^{6}$ en oposición a la

\footnotetext{
Intervención profética de Peter Burke en la mesa D sobre el 'Tournant critique' de Annales: The comtemporary historical world is polycentric, in the sense that innovations now arise in many different places, notably in the so-called 'peripheries', in Europe and outside. Historia a Debate. I. Pasado y futuro. Santiago, 1995, p. 52.

2 ASTARITA, Carlos. Estudio preliminar a José Luis Romero. Crisis y orden en el mundo feudoburgués [1980], Buenos Aires, 2003, p. XXVI.

3 El valor intelectual e historiográfico de la obra de José Luis Romero es también consecuencia de su escaso interés por una "convencional carrera académica" (loc. cit., p. XXX), y de su compromiso ciudadano, Luis Alberto Romero aporta datos significativos sobre una "marginalidad institucional" agudizada por sus ideas liberales y socialistas: "Solo entre 1958 y 1965, apenas ocho años, tuvo una experiencia universitaria plena". ROMERO, Luis Alberto. Luis Romero: una historia ejemplar. $L a$ Nación, 4 de abril de 2009. Disponible en: http://www.lanacion.com.ar/nota.asp?nota_id=1113936.

4 Maravilloso testimonio de su pensamiento maduro, ibídem.

5 LUNA, Félix. Conversaciones con José Luis Romero. Sobre una Argentina con Historia, Política y Democracia. Buenos Aires, 1976, p. 138.

6 Con Imago Mundi Romero pretendió, en 1953, una "toma de posición en el campo historiográfico" defensora de "una concepción integral de la historia que no terminaba en la historia política", ibídem.
} 
academia argentina de los años 50, la verdad es que nunca le abandonó cierto sentimiento de relegación, extensible a los años 60 y 70, también patente en el ámbito internacional, dominado en aquel entonces por Annales y el marxismo historiográfico, corrientes teóricamente próximas a su posición historiográfica. No sobra insistir en que de su carácter relativamente "aislado" y "periférico" en la historiografía del siglo XX, deriva no poco su actualidad y proyección de futuro.

\section{Un historiador fuera de carril}

El desarrollo de José Luis Romero como historiador discurre paralelo al nacimiento y difusión de Annales (la revista nace en 1929, cuando él tenía ya 20 años) y la historiografía marxista. En general, no se consideró ni le consideraron seguidor de tan importantes movimientos historiográficos, pese a la evidente semejanza de temas y enfoques de investigación e interpretación. Annales y el marxismo historiográfico, conjuntamente y por separado, fueron ciertamente tendencias pujantes y preponderantes en los años 60-80, entre los historiadores avanzados de las universidades europeas y latinoamericanas. ${ }^{7}$ También gracias a la colaboración entusiasta y paradójica de José Luis Romero, principalmente en Argentina, donde introdujo -y tradujo-autores principales de Annales y marxistas a través de su cátedra y centro de Historia Social General $(1958)^{8}$ en la Universidad de Buenos Aires. Yo mismo, cuando hace más de dos décadas leí por vez primera a Romero, como medievalista e historiador social de las mentalidades, lo consideré -simplemente- un historiador influido por la escuela francesa y el marxismo, pese a la originalidad de su obra, nada habitual entre los seguidores "periféricos" de las "grandes escuelas" europeas del pasado siglo.

José Luis Romero fue, por tanto, un historiador "fuera de carril". Casi todos los que lo han estudiado coinciden en resaltar su "espíritu libre", "autonomía intelectual" e "independencia de criterio", en general y en su relación con las tendencias historiográficas de su tiempo, de las cuales gustaba aparecer ciertamente distante. ${ }^{10}$ Pero no por falta de visión colectiva de la historia y capacidad personal de compromiso.

\footnotetext{
BARROS, Carlos. El paradigma común de los historiadores del siglo XX, Medievalismo, Madrid, $\mathrm{n}^{\circ}$ 7, 1997, p. 235-262. Disponible en: (www.h-debate.com/cbarros/spanish/paradigma_comun.htm).

8 Desde donde "impulsó la renovación entre los historiadores, conjugando diversas corrientes nuevas, como la francesa de Annales, la del desarrollo económico y la marxista": ROMERO, Luis Alberto. José Luis Romero: una historia ejemplar, op. cit.

9 Sería lamentable confundir la singularidad innovadora, creativa y constructiva de Romero con el individualismo típico de nuestro medio, con frecuencia academicista y conformista, provocador en ocasiones de un hipercriticismo destructivo.

10 "Era algo ambiguo" ante las corrientes historiográficas del momento, reconoce prudentemente
} 


\section{Carlos BARROS. José Luis Romero y la Historia del siglo XXI.}

Romero hizo algo más difícil, poco común entre académicos de ayer y de hoy: actuar como un "hombre de partido", sin abandonar la investigación y otras actividades universitarias, durante los 16 años (1945-1961) de militancia más o menos activa -según qué épocas- en el histórico Partido Socialista argentino. ${ }^{11}$ Adhesión política movida por ideales de igualdad y progreso social, militancia desinteresada al ser el PS de una fuerza de oposición con nulas perspectivas de alcanzar cuotas de poder en la Argentina peronista (1945-1955) y aun posteriormente. Después de la caída de Perón, José Luis Romero fue impulsado -desde la base estudianti $1^{12}$ - al rectorado de la Universidad de Buenos Aires (1955-1956) ${ }^{13}$, que ejerció sin dejar de lado su compromiso socialista, todo lo contrario. Llega a ser uno de los dirigentes importantes del Partido Socialista entre 1956 y $1960^{14}$, alineado hasta donde pudo con su corriente más juvenil e izquierdista. ${ }^{15}$ Formada por jóvenes estudiantes y docentes vinculados muchos de ellos a Romero ${ }^{16}$ por medio de su cátedra de Historia Social General en la UBA, tertulias en su casa, etc. ${ }^{17}$ Difícilmente un hombre así, capaz de compatibilizar la militancia socialista (incluyendo sus desagradables luchas internas ${ }^{18}$ ) con la investigación y la

Luis Alberto Romero en "José Luis Romero: una historia ejemplar". op. cit.

${ }^{11}$ ACHA, Omar. La trama profunda. Historia y vida en José Luis Romero. Buenos Aires, 2005, p. 44-61.

${ }^{12}$ Idem, Ibdem, p. 51.

${ }^{13}$ A decir de Luis Alberto Romero y otros, el rectorado de José Luis Romero constituyó "la más brillante etapa de la Universidad de Buenos Aires" (La Nación, 4 de abril de 2009), consiguiendo en sus siete meses de gestión desplazar del poder al catolicismo integrista y sacar adelante la reforma universitaria. ROMEO, Luis Alberto, Prólogo a José Luis Romero, Latinoamérica, las ciudades y las ideas, Buenos Aires, 2001, p. XI-XII.

${ }^{14}$ La prolongada espiral de división y fragmentación interna del Partido Socialista iniciada en 1958, y el contexto de radicalización política (véanse las notas 15, 73), acabaron por distanciarlo de manera irreversible, en la primera mitad de los años 60, del partido, de la política activa y de la institución universitaria (véase la nota 74).

${ }^{15}$ Hasta que "en 1962 decidió que no podía seguir ni a quienes se incorporaban al peronismo ni a los que optaban por la lucha armada". ROMERO, Luis Alberto. José Luis Romero: una historia ejemplar, op. cit.

${ }^{16}$ También Marc Bloch se vio influido por estudiantes y jóvenes colegas, además de por sus hijos, cuando entra en la resistencia antinazi de Lyon; recomendado por un estudiante de filosofía de 20 años, Maurice Pessis, Bloch comparece ante un dirigente clandestino, a quien le dice humildemente (tiene 57 años y morirá fusilado un año después): "Sí, yo soy el novato de Maurice". FINK, Carole. Marc Bloch. Uma vida na história. Oeiras, 1995, p. 283-284, 303. Ed. original, Cambridge, 1989.

${ }^{17}$ Donde se discutían copias de libros y artículos de la nueva historia social en paralelo con un compromiso político de orientación marxista -que implicaba a una parte de los asistentes-influido por la evolución de la exitosa revolución cubana. ACHA, Omar, op. cit.

${ }^{18}$ Con la cura de humildad que suponía para un historiador conocido y valorado soportar las refriegas de la política partidaria de las izquierdas; algunos utilizaron contra Romero, en los debates internos, su estatus intelectual y académico, con las típicas insidias de que no comprendía las reglas 
vida académica, tendría reparos de soberbia, academicismo o personalismo para formar parte de unas corrientes historiográficas ${ }^{19}$ por su carácter colectivo. En el caso de José Luis Romero, su justificación como "historiador-fuera de carril", en tiempos de fuertes compromisos de todo tipo, hay que buscarla por otro lado.

Romero fue un historiador singular, crítico y creativo, con una ambición historiográfica ${ }^{20}$ que lo situaba por encima de la mayoría de los historiadores de su tiempo ${ }^{21}$ y le condujo a ingentes proyectos de investigación histórica y teórica. Además de interesarse continuamente por la historia de Argentina y América Latina, madura tres grandes objetivos históricos-historiográficos ${ }^{22}$ : una historia general de Europa y Occidente (Proceso histórico del mundo occidental ${ }^{23}$ ), una monumental historia urbana ( $L$ a ciudad occidenta ${ }^{24}$ ), y una teoría de la historia (Teoría general de la vida histórica), que quedaron inconclusos por la brevedad de lo humano individual ${ }^{25}$ y la variedad de dimensiones que ocuparon su tiempo vital,

de la política, conduciéndose mediante "abstracciones de realidad... citas de citas o comentarios de glosas". ACHA, Omar, op. cit., p. 53-54.

${ }^{19}$ Una hipotética pertenencia, explícita y reconocida, de Romero a las escuelas de Annales o marxista le habría aportado, a qué dudarlo, una mayor proyección nacional e internacional (véase la nota 36).

${ }^{20}$ La ambición de Romero era, desde luego, realizable dado su talento para conectar trabajo empírico y reflexión teórica; tenía además determinación, "optimismo radical” (ROMERO, Luis Alberto. José Luis Romero: una historia ejemplar, op. cit.) y capacidad de trabajo; en consecuencia, su ambición venía siendo una virtud profesional, una bendición para la historia, peligrosa por consiguiente para sus posibles competidores (véase la nota 27).

${ }^{21}$ Romero era equiparable en obra y ambición con el Marc Bloch de la Sociedad Feudal (1939), el Fernand Braudel del Mediterráneo (1949) y el Jacques Le Goff de la Civilización del Occidente Medieval (1965), separándose de ellos en lo teórico: ninguno de los representantes de la gran escuela de Annales -ni tampoco de Past and Present, todo hay que decirlo- se atrevió siquiera a proyectar algo así como una teoría general de la vida histórica; tampoco fueron capaces en general de transcender sus especialidades académicas (más fuertes en Europa que en América Latina), mientras que el historiador argentino, aún considerándose medievalista, hizo además mucha y buena historia antigua, moderna y contemporánea: otro rasgo "fuera de carril".

${ }^{22}$ LUNA, Félix, op. cit., p. 127-128.

${ }^{23}$ De los cuatro tomos previstos del Proceso histórico del mundo occidental se redactaron y publicaron los dos correspondientes a la Edad Media (el segundo, póstumamente): La revolución burguesa en el mundo feudal (1967) y el ya citado Crisis y orden en el mundo feudoburgués (1980), del que se hizo una segunda edición, en 2003, con espléndidos prólogos de Jacques Le Goff y Carlos Astarita.

${ }^{24}$ Acaba de publicarse, en base a sus clases y algunos textos (1965-1973), por iniciativa de su hijo Luis Alberto Romero, historiador y albacea de nuestro universal historiador (con la ayuda de su nieta, Laura Muriel): La ciudad occidental. Culturas urbanas en Europa y América. Buenos Aires, 2009.

${ }^{25}$ Cuando se jubila tempranamente de la UBA en 1965, con 56 años, se plantea culminar sus grandes proyectos historiográficos y teóricos (plan iniciado a los 27 años, - ROMERO, Luis Alberto. Prólogo a Latinoamérica, las ciudades y las ideas, p. III) contando con disponer de 20 años de "vida intelectual útil" (ROMERO, Luis Alberto. Prefacio a La ciudad occidental, p. 11), que la naturaleza redujo a 12 años al morir imprevistamente como ya dijimos en 1977, con 68 años, durante un viaje al Japón para asistir al Consejo Directivo de la Universidad de las Naciones Unidas. 


\section{Carlos BARROS. José Luis Romero y la Historia del siglo XXI.}

enriquecieron su vida terrena (la espiritual continúa en la memoria familiar, histórica e historiográfica) y coadyuvaron a formarlo como historiador de excepción.

El problema de la difusión e irradiación internacional de la obra de historiadores importantes, y las corrientes colectivas que puedan generar, es que dependen más del lugar donde nacen y se desarrollan humana y académicamente, y por lo tanto del idioma en que se expresan, que de la propia calidad, novedad y profundidad de sus investigaciones y reflexiones. ${ }^{26}$ José Luis Romero era argentino, ni francés ni inglés, ${ }^{27}$ y pretendía ni más ni menos que reescribir la historia de Europa y del mundo, desde Roma hasta el siglo XX. Es obvio que, desde América Latina, Romero no hubiese podido dirigir una tendencia historiográfica organizada por el mismo ${ }^{28}$ de ámbito internacional como hubiese correspondido por su temática y enfoques de orden global, aun teniendo la capacidad y las ideas para ello, surgidas de la productiva ${ }^{29}$ vía de nutrirse de escuelas divergentes para crear una metodología y teoría propias. ${ }^{30}$ Tampoco generó un movimiento historiográfico de ámbito nacional, por motivos distintos: la influencia agobiante del positivismo (tanto clásico como revisionista) y el tipo de marxismo que imperaba en la Argentina de su tiempo. ${ }^{31}$ Aunque lo intentó modestamente a través de Imago Mundi. Revista de Historia de la cultura (1953-1956), con anhelos de

\footnotetext{
${ }^{26}$ Véase el párrafo a que hace referencia la nota 135.

${ }^{27}$ Sergio Bagú dice, justamente, que La revolución burguesa de Romero está al nivel de la obra de Bloch y se pregunta por qué no ha sido traducida al francés o al inglés, respondiendo que "se trata de un problema vulgar de competencia profesional, porque su autor es un latinoamericano que escribe sobre un tema europeo". De historia e historiadores. Homenaje a José Luis Romero, México, 1982, p. 37; la cuestión, con todo, va más allá que la mezquina envidia-extendido vicio académico- $\mathrm{y}$ los celos profesionales, tiene que ver con el condicionamiento -decisivo en los siglos XIX y XX-de las relaciones académicas por las relaciones económicas y políticas entre lenguas, países y continentes. ANSALDI, Waldo, José Luis Romero, la mala suerte de nacer en el Sur.Revistae-l@tina,v.7, n. 27, abril-junio de 2009.

${ }^{28}$ Tampoco le ofrecieron, según veremos más adelante, jugar un papel mínimamente relevante en la escuela de Annales, cuyos dirigentes y representantes siempre fueron franceses, incluso después de su internacionalización, a partir de la II Guerra Mundial, que siguió el viejo esquema centro-emisor / periferia-recepción.

${ }^{29}$ El ejemplo mayor es Carlos Marx que se inspiró en el idealismo hegeliano, la economía política burguesa y el socialismo utópico, para construir su teoría materialista y dialéctica de la historia, la economía y la política.

${ }^{30}$ ASTARITA, Carlos, op. cit., p. XXX.

${ }^{31}$ El contexto político de esta bipolarización historiográfica cambia en 1983, y José Luis Romero, que había muerto cinco años atrás, "devino un padre fundador de la historiografía argentina" (ACHA, Omar, op. cit., p. 171); fama póstuma debida sobre todo a los proyectos desarrollados después de su jubilación, entre 1965 y 1977, años en los que, precisamente, "su estilo intelectual, riguroso y matizado, no encajaba con la polarización militante de entonces. Mucho menos, en tiempos de revolución, sus aspiraciones democráticas y socialistas...". ROMERO, Luis Alberto, José Luis Romero: una historia ejemplar, op. cit.
} 
"historia total" ${ }^{\text {"32 }}$, que respondía a una clara intención de organizar una tendencia intelectual de base historiográfica: "El subtítulo de IMAGO MUNDI caracteriza exactamente a esta revista, mediante la cual quiere sumarse a una corriente de pensamiento..." (editorial en el $\mathrm{n}^{\mathrm{o}} 1$ ). A la hora del balance, Romero destaca ante todo, veinte años después, el papel político de grupo de Imago Mundi ${ }^{33}$ en la renovación de la Universidad pos-peronista, aportando contactos con la nueva generación estudiantil que llevará al propio Romero al rectorado de la $U_{B A}{ }^{34} \mathrm{y}$ relanzará después hasta el límite su compromiso socialista, según vimos.

En realidad, el historiador Romero no fue más allá de formar sus discípulos y rodearse de colegas más jóvenes, por medio de la docencia docente en el UBA y las reuniones en su casa, tampoco pretendió otra $\operatorname{cosa}^{35}$, y no parecía que quienes lo rodeaban y sostenían le demandasen que organizara una tendencia historiográfica, al menos con la misma intensidad que le pidieron que encabezará el cambio universitario en Buenos Aires, primero, y la tendencia izquierdista en el Partido Socialista argentino, después. Experiencias políticas breves, en tiempos de grandes cambios, que demostraron que Romero podía estar a la altura de las circunstancias poniéndose temporalmente al frente de colectivos en ámbitos más difíciles y duros que los estrictamente historiográficos.

Ante la falta de opciones reales para constituir una corriente de historiadores a la medida de sus propuestas y ambiciones, se entiende finalmente que el historiador Romero hiciese de la necesidad virtud y dedicase su tiempo a cultivar una obra individual ${ }^{36}$, sin casi citar a sus pares, nacionales e internacionales: solamente las fuentes ("tan documentalista como cualquiera", declara suspicaz ${ }^{37}$ ) y lo que salía de su propia cabeza, florida donde las haya. Le llegó incluso a

\footnotetext{
32 Véase la nota 6.

${ }^{33}$ Constituido por críticos del peronismo: "los mejores intelectuales marginados de la universidad, junto con el grupo más joven y contestatario de la revista 'Contorno”. ROMERO, Luis Alberto. José Luis Romero: una historia ejemplar, op. cit.

${ }^{34}$ LUNA, Félix, op. cit., p. 140-141.

${ }^{35}$ En la cátedra de Historia Social General, Romero no parecía interesado en generar consenso tan sólo debate (que no era poco). ASTARITA, Carlos, op. cit., p. XXIX. Sobre la evolución dispar posterior de los asistentes a su cátedra, véase una lista de participantes en Waldo Ansaldi (José Luis Romero, la mala suerte de nacer en el Sur, op. cit.), quien ratifica nuestra interpretación: "No dejó discípulos, al menos en el sentido estricto de la expresión. Los avatares políticos del país tampoco contribuyeron a que generara una 'escuela'... También aquí [en Argentina] tuvo la mala suerte de nacer en el Sur. Pero sigue siendo, como decía Romano, uno de los grandes".

${ }^{36}$ La diferencia con los historiadores europeos más significativos de las vanguardias siglo XX es una representatividad colectiva que promovió altamente sus obras individuales; no fue el caso de Romero, salvo para quienes lo podamos considerar hoy en día precursor de nuestras posiciones historiográficas.

37 op. cit., p. 23.
} 


\section{Carlos BARROS. José Luis Romero y la Historia del siglo XXI.}

decir a Félix Luna: "yo no soy un devoto". ${ }^{38}$ Se refería concretamente a Dilthey, pero vale también para comprender una actitud que se repite en Romero ante otras figuras intelectuales, del pasado y del presente, sobre todo si se trataba de historiadores. Sólo desde una interpretación superficial se puede confundir su oposición a la idolatría de los considerados "grandes autores" con la vulgar arrogancia. ${ }^{39}$ Vicio mimético que no tenía además sentido, en los años 50 , hacia historiadores contemporáneos suyos como, por ejemplo, Febvre y Braudel, que sólo después alcanzaron la fama de "grandes historiadores", gracias al movimiento que supieron desencadenar o mantener.

Justo es reconocer, por otro lado, que las tendencias historiográficas más activas e influyentes en el siglo XX, marxismo y Annales, aunque organizadas y efectivas, desarrollaron una cierta estrechez de miras, con sus dosis de dogmatismo y sectarismo. ${ }^{40}$ Las circunstancias agravantes en el trato recibido por una figura ilustrada como Romero fueron: el tipo de marxismo mayormente difundido en la Argentina de su tiempo, ${ }^{41}$ y su ubicación periférica para una escuela tan jacobino-centralista como la francesa: el único trabajo que publicaron en la revista Annales de José Luis Romero, pese a antiguas relaciones con sus promotores, versó precisamente sobre la influencia francesa sobre la historiografía latinoamericana, o al menos así lo entendieron sus editores ${ }^{42}$ : Les problèmes de l'histoire sociale en Amérique Latine (1965). ${ }^{43}$ Nunca hubiesen aceptado, por lo demás, un trabajo suyo de mayor ambición; tampoco reseñaron sus obras ${ }^{44}$ : a Romero le tocaba como latino un papel subalterno en la escuela francesa, y lo sabía. Aunque no hay mal que por bien no venga. El hecho de mantenerse Romero organizativamente, en los años 50-60, al margen de Annales y del marxismo

38 Idem, Ibidem.

39 Arrogancia académica más típica que quienes, incapaces de cualquier humildad, se muestran superiores y altaneros sin aportar compromisos y alternativas (véanse las notas 9, 18).

${ }^{40}$ Las escuelas historiográficas no escaparon del hábito - muy del "siglo de los extremos"- de estimar que sólo lo propio vale y que el “deber” de su imposición hace necesario descalificar las propuestas del otro; tanto es así que nos ha costado identificar los paradigmas compartidos que tanto han renovado nuestra disciplina (véase la nota 7).

${ }^{41} \mathrm{La}$ "aplicación mecánica y esquemática de los criterios más rudimentarios del análisis marxista", condicionados por la "política del partido", constituyen un problema general del marxismo historiográfico latinoamericano del siglo XX. GUERRA, Sergio. Tres estudios de historiografia latinoamericana. Morelia, 2002, p. 151 ss.

42 Véase la manipulación del título en la nota 99.

${ }^{43}$ Annales, 1965, vol. 20, nº 2, p. 209-215.

${ }^{4}$ He encontrado solamente una cita de La revolución burguesa incluida por Jacques Le Goff - que siempre lo valoró - en un artículo sobre la encuesta de Centre des Recherches Historiques sobre las ordenes mendicantes. Annales, 1970, vol. 25, nº 4. 
mayoritario en Argentina tuvo, por otro lado, la ventaja de mantenerle asimismo al margen de los errores y las desviaciones economicistas (determinismo vulgar), estructuralistas (negación del sujeto histórico) y sectarias (conmigo o contra mí), que tanto contribuyeron a la decadencia de los Annales braudelianos y del marxismo elemental, y -desde los años 80 - a la supervivencia y renovada actualidad de la historiografía de Romero, que hoy celebramos y redescubrimos.

\section{El marxismo de Romero}

Si algo me ha sorprendido de las lecturas historiográficas que acabo de hacer sobre Romero, a fin de completar y ampliar mi anterior conocimiento de su obra medievalística, es un extendido interés por "negar" su marxismo ${ }^{45}$ : Romero "no era marxista.... Sabía que no lo era y acertaba" ${ }^{46}$ Elegimos este seguro bienintencionado $^{47}$ rechazo de Sergio Bagú por su contundencia y tipo de argumentación: justifica la distancia de Romero del marxismo por su formación humanista (como si no hubiese existido un humanismo marxista ${ }^{48}$ ), porque no siempre coincidía con Marx (sólo la escolástica marxista lo hace) y le interesaba poco la economía

\footnotetext{
${ }^{45}$ Impugnación del Romero marxista que acabó afectando a su relación con la juventud estudiantil, incluyendo su propio hijo: "comencé a inquietarme por las críticas que circulaban en el ambiente estudiantil. Particularmente las de quienes ponían en duda 'el marxismo de Romero'. Mis lealtades estaban en conflicto, pues en mi Facultad, en los tempranos sesenta, nada valioso podía existir fuera del marxismo". ROMERO, Luis Alberto. José Luis Romero: una historia ejemplar, op. cit.

${ }^{46}$ BAGÚ, Sergi, op.cit., p. 37-38.

${ }^{47}$ Estamos seguros de que el "no marxismo" de Bagú tenía el mismo sentido que en Marx cuando le confesó a Lafargue, a finales de los años 70 del siglo XIX: "Ce qu'il y a de certain, c'est que moi je ne suis pas marxiste"; criticando la simplificación de su pensamiento por determinados "marxistas" franceses (carta de Engels a Bernstein, 2 de noviembre de 1882).

${ }^{48}$ El autor y político más representativo en América Latina de esta corriente interna del marxismo fue Salvador Allende que dijo en 1971: "Pisamos un camino nuevo; marchamos sin guía por un terreno desconocido; apenas teniendo como brújula nuestra fidelidad al humanismo de todas las épocas -particularmente al humanismo marxista" http://es.wikipedia.org/wiki/Marxismo_humanista; con anterioridad Alexander Dubcek intentó en Checoslovaquia un "socialismo de rostro humano" (1968); en Europa importantes teóricos marxistas, de tradición política comunista y/o socialista, definieron y reivindicaron el humanismo marxista: GRAMSCI, Antonio. Cuadernos de la cárcel. Buenos Aires, 1958-1962, véase la nota 62; SARTRE, Jean-Paul. Crítica de la razón dialéctica. Buenos Aires, 1963; SCHAFF, Adam. La filosofía del hombre. Buenos Aires, 1964; así como Ernest Bloch, Roger Garaudy, Herbert Marcuse y otros presentes en el volumen colectivo coordinado por FROMM, Eric. Humanismo socialista. Buenos Aires, 1966; para una visión plural del marxismo resulta útil: KOLAKOWSKI, Leszek. Las principales corrientes del marxismo. 3 vol., Madrid, 1980; GOULDNER, Alvin W. Los dos marxismos. Madrid, 1980; en Argentina era bien conocida, por lo demás, la posición del intelectual italoargentino MONDOLFO, Rodolfo. El humanismo de Marx. México, 1964; véase también PONZA, Pablo. Existencialismo y marxismo humanista en los intelectuales argentinos de los sesenta. 2006, disponible en: http:// nuevomundo.revues.org/index2923.html.
} 


\section{Carlos BARROS. José Luis Romero y la Historia del siglo XXI.}

(confundiendo marxismo con economicismo). Prueba de que, en Argentina, imperaba como ya dijimos un marxismo de catecismo, esquemático, fruto de una codificación estalinista que tuvo una especial difusión, precisamente, en los países latinoamericanos en los años de Romero por la férrea dependencia económica, política e ideológica de la Unión Soviética de sus partidos comunistas nacionales.

Afortunadamente tenemos, contradiciendo la "negación" de su amigo Bagúu, la propia palabra de José Luis Romero, además de su obra. Romero así como adopta una postura de silencio espeso ante Annales (como si prefiriese no decir lo pensaba $^{50}$ ), explicita de manera apasionada, nítida y sugerente su deuda con el marxismo de Marx. Ante Félix Luna, iniciada ya la dictadura militar, Romero se declara marxista ${ }^{51}$ : "creo sinceramente que en el mundo contemporáneo hay muy poca gente que, en alguna medida, no sea marxista... si se entiende por marxismo -y es su expresión más válida- un conjunto de principios de la dinámica histórica"'52. Criticando, como otros autores, marxistas y no marxistas, la subestimación del "papel de las ideas en la historia",53 que Engels reconoció, en los años 90 del siglo XIX, al decir autocríticamente como él y Marx se vieron "obligados" a subrayar, ante el idealismo dominante, el papel de la economía en la historia. ${ }^{54}$ La lectura no dogmática y crítica que Romero hacía del Marx original, que como bien sabemos

\footnotetext{
${ }^{49}$ Preservando la originalidad de Romero, inasimilable al marxismo latinoamericano, Sergio Bagú defiende su propia especificidad y alta creatividad, como historiador asimismo deudor el marxismo; véase MILLÁN, Márgara. Sergio Bagú: los caminos de la historiografía. Estudios latinoamericanos, México, 1994, año I, $\mathrm{n}^{\circ} 1$.

${ }^{50}$ Véase la nota 85.

${ }^{51}$ Un acto de valor: el 24 de marzo de 1976 los militares habían tomado el poder y las entrevistas tuvieron en lugar en los meses de setiembre y octubre del mismo año, la editorial Siglo XXI donde participaba y publicaba Romero, había sido allanada por los golpistas, y el editor de Conversaciones con José Luis Romero, que publica en diciembre de 1976, Jacobo Timerman, "desaparece" meses después. ROEMRO, Luis Alberto. Prólogo a Latinoamérica, las ciudades y las ideas, p. I.

${ }_{52}^{52}$ LUNA, Félix. op.cit., p. 91.

${ }^{53}$ Idem, Ibidem, p. 93.

${ }^{54}$ Carta a Karl Schmidt (27/10/1890): "lo que nosotros llamamos 'concepción ideológica' repercute a su vez sobre la base económica y puede, dentro de ciertos límites modificarla"; Carta a Franz Mehring (14/7/1893): "ni Marx ni yo hemos hecho bastante hincapié en nuestros escritos... En lo que nosotros más insistíamos -y no podíamos por menos de hacerlo así- era en derivar de los hechos económicos las ideas políticas, jurídicas, etc., y los actos condicionados por ellas. Y al proceder de esta manera, el contenido nos hacía olvidar la forma, es decir el proceso de génesis de estas ideas, etc. Con ello proporcionamos a nuestros adversarios un buen pretexto para sus errores y tergiversaciones". MARX, Carlos; ENGELS, Federico. Obras escogidas. vol. 2, Madrid, 1975 , p. 527, 530.
} 
gustaba de no considerarse marxiste $e^{55}$, era asimismo consecuencia de su oposición a la degeneración autocrática y burocrática de la revolución bolchevique. ${ }^{56}$

La verdad es que la mejor parte del "marxismo occidental" (Perry Ander$\operatorname{son}^{57}$ ) de los años 60 y 70 se parecía más a lo que decía Romero que a lo que se entendía mayoritariamente por marxismo en Argentina y Latinoamérica ${ }^{58}$ (salvo excepciones ${ }^{59}$ ) en su tiempo. ${ }^{60}$ Queremos decir que Romero en Europa hubiese sido considerado marxista, y se hubiese aceptando con mayor normalidad la importancia que le daba a conceptos extraídos de otras tradiciones filosóficas e historiográficas, a la manera del Marx original. Hubiese tenido su lugar natural entre los historiadores marxistas de Gran Bretaña ${ }^{61}$, Francia, Italia y España (influidos también, como los historiadores marxista franceses, por Annales). Con todo José Luis Romero desarrolló, desde Buenos Aires, una obra historiográfica individual con ciertos paralelismos temáticos y de enfoque con los Quaderni del Carcere (1929-1935) de Antonio Gramsci, fundador del Partido Comunista Italiano $^{62}$ : antidogmatismo, antiestalinismo; inspiración conjunta en Marx, Ma-

\footnotetext{
55 Véase la nota 47.

56 ACHA, Omar, op. cit., p. 74.

57 ANDERSON, Perry. Consideraciones sobre el marxismo occidental. Madrid, 1979.
}

${ }^{58}$ Del marxismo-leninismo estalinista de los viejos P. CC. se pasó en los años 70 al marxismo estructuralista de Althusser, propagado exitosamente a modo de catecismo en América Latina por Marta Harnecker a partir de 1969, sin que hiciese demasiado efecto la crítica feroz de E. P. Thompson (Miseria de la teoría, Barcelona, 1981), respondida por Anderson (Teoría política e historia. Un debate con E. P. Thompson, Madrid, 1985), donde se demuestra que este último no supo ni quiso ver las diferencias esenciales entre el marxismo occidental en su conjunto (dominado por la escuela de Frankfurt y Antonio Gramsci) y el neoestalinismo althusseriano.

59 Ante todo, el intelectual y líder peruano del socialismo de izquierdas José Carlos Mariátegui (1894-1930), formado en Italia donde conoció a Gramsci y la obra de Labriola, Croce y Maquiavelo (véase su obra La defensa del marxismo -1930 - en: www.lahaine.org/index.php?p=34904).

${ }^{60}$ Véase la nota 41.

${ }^{61}$ La revista Past and Present, creada en 1952 por el grupo de historiadores del Partido Comunista Británico, generó sin duda la escuela o corriente más valiosa de la historiografía marxista del siglo XX, incluyendo en su seno sin asomo de sectarismo a historiadores liberal-progresistas como Lawrence Stone o John Elliott.

${ }^{62}$ Con seguridad Romero habló de Gramsci con los obreros de la construcción italianos “comunistas y filósofos" que laboraron en su casa de Adrogué (ROMERO, Luis Alberto. "José Luis Romero: una historia ejemplar", loc. cit.), desconocemos si hubo, o hay, obras originales del gran italiano en sus bibliotecas de Adrogué (1948) o Pinamar (1958); el pensamiento teórico-político de Romero estaba, por otro lado, ya formado (Luis Alberto suele decir que, en un momento dado, dejó de seguir las revistas académicas y leer a otros autores. Prólogo a Latinoamérica, las ciudades y las ideas, p. VIII) cuando el intelectual comunista Héctor Pablo Agosti edita en Argentina los Cuadernos de la Cárcel en su versión temática (Editorial Lautaro) entre 1958 y 1962, y jóvenes gramscianos fundan en 1963 la editorial Pasado y Presente (siendo expulsados ipso facto del prosoviético Partido Comunista Argentino), difundiendo el pensamiento gramsciano y otros marxismos críticos y minoritarios en Argentina y el universo latino. BURGOS, Raúl. Los grams- 
quiavelo y Benedetto Croce (al igual que Mariátegui ${ }^{63}$ ); enfatizar en el papel de las ideas y la cultura ( $\sin$ renunciar al estudio de la sociedad, el poder y la economía, como buenos marxistas).

Otra discrepancia de Romero con la ortodoxia marxista, comunista y revolucionaria, derivada de su propia formación político-cultural que se vio reforzada por los resultados obtenidos en la Unión Soviética y su zona de influencia, es su temprano posicionamiento en favor de un socialismo reformista y democrático, cuya inspiración marxista reivindicaba con claridad ${ }^{64}$ : "La relación entre la teoría y la política en Marx, en mi opinión, no es unívoca, no hay una política para una teoría: hay una teoría y muchas políticas posibles". ${ }^{65}$ No sólo en su opinión, obviamente: cualquiera persona culta e informada sabe que el marxismo inspiró la II Internacional socialista, creada en 1889 por Engels (Marx muere en 1883) para aglutinar a los partidos socialistas o socialdemócratas que adoptaron el marxismo como principio rector cuando menos hasta bien avanzado el siglo $\mathrm{XX} \cdot{ }^{66} \mathrm{El}$ propio Engels apoyó explícitamente, antes de su muerte en 1895, la posibilidad de acceder democrática y pacíficamente al poder en Alemania con su partido socialdemócrata. La escisión del partido bolchevique y la izquierda de Zimmerwald para formar la III Internacional Comunista en 1919, no significó por lo demás la desaparición de una Internacional Socialista, reconstruída en 1951, que mantuvo vivo internacionalmente un socialismo marxista de tipo reformista, humanista y democrático cuando menos hasta la muerte de Salvador Allende ${ }^{67}$ (1973).

He nombrado al presidente Allende, precisamente por representar en América Latina el primer éxito electoral de un socialismo democrático inspirado en el marxismo, que puso en práctica un reformismo muy revolucionario. ${ }^{68}$ Patente así mismo en los escritos políticos de Romero desde 1948, año de publicación de $E l$ ciclo de la revolución contemporánea, donde acepta que en su culminación el movimiento reformista de orientación socialista habría de acabar por la fuerza con los restos del sistema-capitalista-caduco procediendo "como la maceta constriñe

cianos argentinos. Cultura y política en la experiencia de Pasado y Presente. Buenos Aires, 2005.

${ }^{63}$ Véase la nota 59

${ }^{64}$ Otro caso notorio es el historiador marxista y político socialista chileno, Julio César Jobet (véase GUERRA, Sergio, op. cit., p. 158-160).

${ }^{65}$ LUNA, Félix, op.cit., p. 92.

${ }^{66}$ En España, el PSOE no "renunció" al marxismo en sus estatutos hasta 1978.

${ }^{67}$ Véase la nota 48.

${ }^{68}$ Nada que ver, por consiguiente, con la socialdemocracia que, en América Latina y otros lugares, antes y sobre todo después del socialismo reformista, democrático pero radical, de Romero o Allende, se integró en el establishment, legitimando en algunos países hasta hoy en día las desigualdades y cualquier renuncia a una verdadera transformación social. 
al limonero... Entonces sí habrá llegado el momento de la violencia, más sólo a condición de que el tronco sea robusto y las raíces estén ya desbordando... Antes de ese momento..., la violencia esconde tantos peligros como la injusticia contra la que aparentemente se dirige". ${ }^{69}$ Consecuentemente Romero apoyó de forma abierta la revolución cubana de 1959, y su viraje marxista posterior (denunciando el acoso de la "gran prensa" contra Cuba castrista). Sosteniendo incluso como correcta "la socialización de los medios de producción, único camino para acabar con la situación colonial que caracteriza a la economía cubana" "Cuba: una experiencia", Situación, $\left.\mathrm{n}^{0} 5,1960\right) .{ }^{70}$ Compromiso socialista y marxista que le llevó a participar, fracasado el desembarco de Playa Girón, en actos públicos en solidaridad con Cuba. ${ }^{71}$ La opción posterior por la lucha guerrillera en Argentina, imitando la experiencia cubana, de una parte de los jóvenes socialistas que le seguían, marcó el límite de su compromiso personal ${ }^{72}$, contribuyendo ${ }^{73}$ a su decisión de volver de manera total al estudio y la investigación, abandonando para ello la vida pública y la propia institución universitaria, en $1965 .{ }^{74}$ Así y todo, la historia ¿no le ha dado política y teóricamente la razón a Salvador Allende, por un lado, y a José Luis Romero, políticamente más modesto, por el otro? ${ }^{75}$

${ }^{69}$ ACHA, Omar, op.cit., p. 74-75.

${ }^{70}$ Idem, Ibidem, p. 58.

${ }^{71}$ ANSALDI, Waldo, op. cit.

${ }^{72}$ Seguramente pensaba que no existía, en aquel momento, un movimiento social y socialista en Argentina que desbordara la maceta del capitalismo, y que una violencia revolucionaria generaría - como así fue- una reacción todavía más violenta y destructiva, etc.; además de consideraciones propias que podemos suponer relativas a la edad y la profesión; dos décadas antes, Marc Bloch, con unas circunstancias individuales parecidas (no así el contexto histórico), había ingresado en la resistencia francesa (véase la nota 16) aportando su escritura a la lucha política y armada contra la ocupación nazi (que posibilitaba y justificaba mejor una violencia patriótica), lo que no lo libró - su pacífica pluma- de ser ignominiosamente torturado y fusilado por los alemanes el 19 de junio de 1944

${ }^{73}$ Junto con las críticas que recibía su heterodoxia marxista y la entrada en las filas peronistas (también guerrilleras en los años 70) de la otra parte de los jóvenes socialistas que le venían apoyando. ROMERO, Luis Alberto. Prólogo a Latinoamérica, las ciudades y las ideas, p. XII, XIV (véase también la nota 15 ).

${ }^{74}$ Idem; sobre lo que ganó la historia y la historiografía después de su jubilación política-universitaria, véase la nota 25; la politización de la vida universitaria (sobre todo en la Facultad de Filosofía y Letras de la UBA, hasta hoy) le condujo a tomar esa doble decisión, que tenía su motivación más profunda en la vocación investigadora y reflexiva de José Luis Romero.

${ }^{75}$ Primero, con la "inesperada" transición del llamado socialismo real al capitalismo en el Este de Europa, entre 1989 y 1991, que vino a demostrar la inviabilidad histórica de un socialismo autoritario y burocrático ("dictadura del proletariado"); segundo, con la emergencia y extensión en América Latina, desde 1999, de un movimiento político y social, electoral y gubernamental, reformista-revolucionario en sus intenciones, que se plantea, desde 2005, construir un "socialismo del siglo XXI" en Venezuela, Bolivia y Ecuador, aceptando - por el momento - la propiedad 


\section{Carlos BARROS. José Luis Romero y la Historia del siglo XXI.}

Pero volvamos al marxismo historiográfico que Romero jamás abandonó, como componente esencial de su pensamiento histórico, en contraste con un socialismo reformista pero marxista que tuvo que sentir fracasado en 1973. Romero utiliza con su rigor habitual en los análisis políticos de los años 50 la terminología de clase, lucha de clases, clase obrera, proletariado, enemigo de clase... ${ }^{76} \mathrm{Con}$ un lenguaje más académico, y adaptado a la Edad Media (donde no había clase obrera), pero no menos marxista nos habla, veinte años después, en la obra que dejó inédita sobre la crisis bajomedieval, de "conflictos" y "tensiones sociales" entre burguesía y clase nobiliaria, de clases dominantes y clases subordinadas, campesinas, urbanas o populares, sin dejar de indagar el dinamismo de las "facciones" y los "grupos sociales". ${ }^{77}$ Ajeno, en este sentido, a un estructuralismo althusseriano que minusvaloraba el papel de subjetividad social y humana en la historia. Más en línea, por tanto, con el Marx humanista y subjetivista de los Manuscritos económicos y filosóficos de 1844 y del Manifiesto comunista de 1848 que del objetivismo, estructural y economicista, del Prólogo a la Contribución a la crítica de la economía política de 1859.

En cualquier caso, el Romero marxista, fiel a sí mismo, tampoco es devoto. Aprovechando la real subestimación de la "influencia de las ideas sobre la realidad" que atribuía a Marx, suelta eso de que: "yo también tengo una teoría de la historia, así que para mi Marx es un competidor". Anunciando que tenía "muy adelantado" un libro sobre "la teoría general de la vida histórica" ${ }^{78}$, que fundamentaba en un "juego de la realidad y las ideas" superando la dialéctica como "unidad de los contrarios" por una "dialéctica múltiple y plural, más variada y menos lógica", puesto que a la vida histórica -añade- se "la distorsiona cuando se intenta explicarla de una manera demasiado racional". ${ }^{79}$ Para lo cual se remonta a Vico, Hegel y Marx, recuperación de las fuentes idealistas de marxismo, que pudo llevarle a encontrar en el camino lo que pudo perderse entre el joven y el viejo Marx. A quién siguió asimismo cuando se puso a estudiar detenidamente,

privada y la democracia representativa, sin reivindicar claramente -todo hay que decirlo- como antecedente la temprana experiencia en Chile de Salvador Allende entre 1970 y 1973; véase BARROS, Carlos. Historia inmediata: marxismo, democracia y socialismo del siglo XXI. Prólogo a MONZANT, José Luis. La conversión de K. La diatriba ideológica del poder. Maracaibo, 2009.

${ }^{76}$ Véanse sus artículos políticos de los años 1957-1958 en ACHA, Omar, op.cit., p. 56-57.

${ }^{77}$ Crisis y orden en el mundo feudoburgués, p. 90-95.

${ }^{78}$ En mi opinión es la pérdida mayor de los proyectos inacabados de José Luis Romero.

${ }^{79}$ LUNA, Félix, op.cit., p. 92-93. 
en la larga duración, la historia de la burguesía con el fin de extraer enseñanzas para implantar un socialismo que habría de superar al capitalismo. ${ }^{80}$

\section{Al margen de Annales}

Si Marx era para Romero un competidor ¿qué serían los historiadores de Annales, sus contemporáneos? En el mejor de los casos, sus iguales ${ }^{81}$; cuando no inferiores por sus deficiencias teóricas.

En 1953, publica en su recién estrenada revista, Imago mundi $i^{82}$, una reseña de la Introducción a la historia ${ }^{83}$ de Marc Bloch, donde reconoce la naciente escuela de Annales, al referirse a "Bloch y su escuela" ${ }^{\$ 4}$, y aplica un doble criterio muy en su estilo: iconoclasta pero comprometido. Por un lado, se muestra sensible y solidario, como buen socialista e historiador progresista, con la lucha de Bloch contra los nazis, admira su humanismo, lamenta las condiciones precarias en las que tiene que redactar la obra -incluso llega a decir por ello que "sería injusto exigir.... mayor rigor y más precisión en el planteo sistemático de los problemas"y se horroriza ante su muerte terrible en 1944. Por el otro, hace una crítica breve pero severa al libro (y por extensión a la escuela de Annales $^{85}$ ) atacando su falta de ambición teórica, valiéndose para ello de la inadecuada traducción -responsabilidad de la editorial- del título original (realmente, son dos, uno de Bloch y otro de Febvre ${ }^{86}$ ) como la Introducción a la historia que no es, por ausencia de una teoría de la historia. Correspondiendo realmente el contenido del libro -ar-

\footnotetext{
${ }^{80}$ ACHA, Omar, op. cit., p. 75.

${ }^{81}$ Compartían la influencia de Henri Pirenne (1862-1935), historiador de su tiempo y precursor de la historia económico-social de la Edad Media europea.

${ }^{82}$ Imago mundi, diciembre de 1953, no 2, p. 99-100.

${ }^{83}$ Libro escrito en 1941-1943 como Apologie pour l'histoire ou Comment et pourquoi travaille un historien; publicado en 1949 por Lucien Febvre como Apologie pour l'histoire ou Métier d'historien (véase la edición crítica de Étienne Bloch, con un prólogo de Jacques Le Goff, 1993, p. 39-42); seguramente Romero no leyó la obra hasta su edición española con título ajeno al autor y presuntamente comercial: Introducción a la historia, FCE, 1952.

${ }^{84}$ Aunque identifica a Febvre como cofundador de Annales, lo sitúa -tal vez, injustamente- en un segundo plano, no lo que es óbice para que aproveche para criticar a Bloch y defender su concepto de "vida histórica" (véase la nota 89), la siguiente cita de, primer editor de Apologie pour l'histoire: "Ni una sola vez, salvo error, aparece en el libro la palabra evolución".

${ }^{85}$ Romero valora de los annalistes sus trabajos de investigación, que casi no los cita aunque los conoce y utiliza sin sectarismo como material docente, al tiempo que se calla bastante -consciente, supongo, de que iban en el mismo barco- para no tener que exponer sus diferencias con ellos de tipo personal, metodológico y teórico; cosa que no hacía con Marx y el marxismo de sus seguidores más cerrados, que eran legión, con los que discrepaba además políticamente.

${ }^{86}$ Véase la nota 83.
} 
gumenta Romero-al subtítulo de Febvre, Métier d'historien (le gustaría más sin duda, el que puso inicialmente Bloch: "Cómo y porqué trabaja un historiador" ${ }^{\text {"7 }}$ ), puesto que tampoco es una "apología por la historia". Sentencia, en resumen, nuestro crítico de Bloch: "parece verse limitado a anotar las observaciones acumuladas a lo largo de un sostenido ejercicio de la investigación". Ello después de iniciar su recensión con las "humildes palabras" de Bloch declarándose un simple "artesano" de la historia, que confiesa haber cultivado "sin creerse por eso matemático". Hace sangre pues Romero de las atribuidas limitaciones pragmáticas y empiristas de Bloch, reconocidas humildemente -insiste Romero- por tan "ilustre medievalista" e "investigador asiduo y sagaz de la sociedad feudal", y también por el propio Febvre en su tarea de editor cuando introduce por su cuenta en el titulo a modo de concreción las palabras "oficio de historiador".

Romero era, desde luego, capaz de trabajar con dos ideas a la vez en la cabeza: a) "vehemente simpatía" con el historiador francés por su compromiso ético-político y trabajo de investigación; b) impugnación sin concesiones de una parte de sus presupuestos de fondo. Reconocimiento sentido de Bloch por su "mucho saber y mucha humanidad, virtudes con las que se hace un buen historiador" $"$, pero dura conclusión final de su corta pero sustancial reseña: "No se busque, pues, en este libro un sistema de la vida histórica ni un cuadro acabado de los problemas del saber histórico". Cuestionando a la par la-posteriormente archiconocida y asumida- definición de historia del fundador de Annales (escribe Romero: "ciencia de los hombres en el tiempo", dice Bloch), porque el historiador argentino considera superior el concepto crociano de "vida histórica" ${ }^{89}$ en lugar de los "hombres en el tiempo": "Bloch no discurre sobre la vida histórica sino en cuanto a objeto de conocimiento, y prefiere reflexionar sobre... una disciplina que quiere alcanzar el más alto rigor". Otra vez, sugiere Romero con sutileza

\footnotetext{
${ }^{87}$ Idem, Ibidem.

${ }^{88}$ Hoy, sin embargo, cuando se dice, ante la caída de las "grandes escuelas", que lo que importa es ser "buen historiador" se suele valorando ante todo el uso de fuentes, el trabajo de archivo. BARROS, Carlos. El retorno de la historia. Historia a debate. I. Cambio de siglo. Santiago, 2000, p. 153-173. Disponible en: http://www.h-debate.com/cbarros/spanish/articulos/nuevo_paradigma/ retornohistoria.htm.

${ }^{89}$ También Antonio Gramsci importa de Benedetto Croce la noción de "vida histórica" que incluye a la vez el objeto y el sujeto, el pasado y el presente, etc., facilitando enfoques de historia total / global; si bien hoy en día, además de insistir en la relación inseparable entre el objeto y el sujeto de la historia, lo más importante es subrayar la interacción continua entre el objeto y el sujeto del conocimiento histórico (historiadores), redefiniendo la historia como una ciencia con sujeto social y sujeto cognoscente (véase punto I del Manifiesto historiográfico de Historia a Debate en: www.h-debate.com/Spanish/manifiesto/manifiesto_had.htm).
} 
un Bloch cuyo positivismo y objetivismo ${ }^{90}$, viene a decirnos, le impide usar conceptos y reflexiones más abstractas (no era "matemático"), cosa que cuando menos Romero intentaba. Probablemente, su lectura de Bloch desde esa simpatía tan competidora le conduce a infravalorar la importancia renovadora - más fácil de ver a posteriori - de Annales y sus libros fundadores ${ }^{91}$, al tiempo que pone en valor la superior ambición, inquietud y conocimiento teórico de sí mismo ${ }^{92}$, junto con la doble y paradójica actitud - jamás explicada - de Annales ante el positivismo alemán: a) cuestionamiento (público) de orden temático como "historia historizante", superficial, descriptiva, política, narrativa, acontecimental, etc.; b) continuidad (oculta) de orden epistemológico de la manera positivista de investigar que tuvo efectos positivos (fuentes) pero también muy negativos ${ }^{93}$ para la "nueva historia" que tanto defendió y promovió la pasada escuela francesa. Paradoja que contribuye no poco a explicar su crisis final y el retorno actual de la vieja historia metódica de Seignobos y Langlois. ${ }^{94}$

Por propia voluntad pero también forzado por el "imperialismo" francés, José Luis Romero se mantuvo en los márgenes de Annales, aunque tuvo sus relaciones personales no fueron al parecer nada buenas en el caso de Fernand Braudel, que dirigió el gran movimiento historiográfico entre 1956 y 1968 de manera especialmente personalista. ${ }^{95}$ Ruggiero Romano, historiador italiano que

\footnotetext{
${ }^{90}$ El propio Romero no quería ser menos "documentalista” que otros, aunque por su formación y posicionamiento tenía claro que había que elevar el umbral intelectual del trabajo de historiador por encima de Annales, superando incluso al materialismo histórico.

${ }^{91}$ El otro es Combats pour l'histoire (1952; trad. esp. Barcelona, Península, 1959) del propio Lucien Febvre, más radical en su antipositivismo temático que Bloch, pero igualmente deficitario en lo epistemológico y lo teórico (si comparamos con los fundadores del marxismo); así y todo, tampoco los historiadores marxistas franceses e ingleses intentaron como Marx -y Romero- trabajar en una teoría de la historia (salvo quizás Gordon Childe, 1892-1957).

92 Descalificado por colegas retardatarios como "filósofo" que no historiador, fueron los saberes e intereses filosóficos y teóricos de José Luis Romero los que le permitieron elevarse por encima de las tendencias de la época (al tiempo que aprendía de ellas), sobreviviendo mejor al fin de la "revolución historiográfica del siglo XX".

93 Véase el apartado II.1 de "Historiografía autocrítica" en BARROS, Carlos. Defensa e ilustración del Manifiesto historiográfico de Historia a Debate.E-l@atina. Revista electrónica de estudios latinoamericanos, UDISHAL, Buenos Aires, vol. 1, números 3 y 4, 2003. Disponible en: http:// www.iigg.fsoc.uba.ar/elatina.htm.

${ }^{94}$ BARROS, Carlos. La Escuela de los 'Annales' y la historia que viene. 2001. Disponible en: www.h-debate.com/cbarros/spanish/articulos/historiografia inmediata/escueladeannales.htm.

95 En 1969, tuvo lugar una asamblea de investigadores de la VI Sección de Ciencias Sociales de la École Practique des Hautes Études en el Collège de France, dónde se decidió reemplazar en la dirección de Annales (1969) -y después en la École (1972) - a Fernand Braudel por el triunvirato formado Jacques Le Goff (presidente de la VI Sección desde 1972), Emmanuel Le Roy Ladurie y Marc Ferro, véase "La contribución de los terceros Annales y la historia de las mentalidades. 1969-1989", loc.
} 


\section{Carlos BARROS. José Luis Romero y la Historia del siglo XXI.}

entró por medio de Braudel en el grupo de Annales y en la École Practique des Hautes Études (donde permaneció hasta 1965), y además amigo y admirador de Romero ("para mi es uno de los grandes"), nos informa elípticamente de lo que pasó entre ellos: "Braudel y Romero de hecho no se entendieron nunca. Braudel sabía que Romero era el historiador más inteligente de Argentina, pero no se entendieron... Tengo cartas, pero de eso no quiero hablar. No se entendieron, punto" ${ }^{96}$. Se sobreentiende que hubo choque de caracteres, también cuestiones de fondo historiográfico, seguro. ${ }^{97}$ Empezando por el problema de la jerarquía internacional de las relaciones historiográficas. ${ }^{98}$ Será justamente durante los segundos Annales de Braudel cuando se intensifican y promueven los rasgos más miméticos de la recepción periférica en parte de Europa y América de la escuela de Annales. ${ }^{99}$ Luis Alberto Romero ha escrito en 2001: “José Luis Romero no

cit.; la principal biógrafa de Braudel evita prudentemente hablar de la defenestración de Braudel en 1969, pero aporta indicios - no por interesados menos útiles- al comentar el radicalismo marxista de la nueva generación de Annales, que ilustra contando los ataques personales que recibió Braudel por parte de algunos de aquellos jóvenes historiadores (Maurice Agulhon, Annie Kriegel; ambos ex miembros del PCF) de un "féroce anti-américanisme" (estábamos en plena guerra del Vietnam, recordemos), por la financiación de las Fundaciones Ford y Rockefeller de la analista VI Sección de la EPHE. GEMELLI, Giuliana. Fernand Braudel. Paris, 1995 (Venezia, 1990), p. 164-165.

${ }^{96}$ Entrevista a Ruggiero Romano en Todo es historia, $\mathrm{n}^{\circ}$ 251, mayo de 1988, p. 38. Disponible en: $\mathrm{http}: / /$ www.elhistoriador.com.ar/entrevistas/r/romano.php.

${ }^{97}$ Véase la nota 99; Romero prefiguró desde Argentina el tránsito, al calor de mayo del 68, de los segundos a los terceros Annales, del "gran patrón" a una dirección colectiva, del estructuralismo económico-social a la historia de las mentalidades, malamente por tanto podía estar de acuerdo con la renuncia braudeliana a la corta duración, las mentalidades y una historia con sujeto social.

${ }^{98}$ La historia de Annales ni sufrió cambios en cuanto a la relación centro-periferia a pesar de Jacques Le Goff, cuya concepción de unos cuartos Annales realmente internacionales, compartimos a principios de los años 90; de la frustración este tournant critique de Annales surgió, en parte, Historia a Debate como foro y tendencia historiográfica internacional pero de iniciativa latina; sobre los terceros Annales (1969-1989) y el intento fracasado de tournant critique (1989). Véase La contribución de los terceros Annales y la historia de las mentalidades. 1969-1989. La otra historia: sociedad, cultura y mentalidades. Bilbao. 1993, p. 87-118. Disponible en: www.h-debate.com/cbarros/spanish/contribucion.htm; La 'Nouvelle Histoire' y sus críticos. Manuscrits. Revista d'Història Moderna, nº 9, Barcelona, 1991, p. 83-111. Disponible en: www.h-debate.com/ cbarros/spanish/nouvelle.htm; El 'tournant critique' de Annales. Revista de Història Medieval, Valencia, nº 2, 1991, p. 193-197. Disponible en: www.h-debate.com/cbarros/spanish/tournant. htm; La Escuela de los 'Annales' y la historia que viene. La historia que se fue, Suplemento Cultural, Diario de Sevilla, no 99, 18 de enero de 2001. Disponible en: www.h-debate.com/ cbarros/spanish/articulos/historiografia_inmediata/escueladeannales.htm.

${ }_{99}$ Braudel publica en Annales ( $\left.\mathrm{n}^{\circ} 2,1965\right)$, el texto de la conferencia en la EPHE cuyo título original era "Los puntos de vista: historia política o historia social", donde Romero proclama que "en todas partes la historia social es inseparable de la historia política", que la historia política no se debe abandonar -como lamentablemente hizo Annales- sino ir a "una total reconsideración" reemplazando los criterios tradicionales de tipo político, "por otros más ricos y complejos", empezando por su entronque con la historia social, anticipando en una o dos décadas la "nueva 
era un seguidor acrítico de Annales" ${ }^{100}$ Desde luego, ni lo era ni podía serlo; tampoco creo que se le pueda en rigor considerar "seguidor", aunque pudiera parecérnoslo por la historia que hacía. Desligazón digamos orgánica de Romero respecto de Annales, en los años 50-70, que no podemos menos que lamentar los que valoramos altamente la pasada escuela francesa, cuyo unilateralismo relacional, con la subsiguiente desvalorización de las culturas históricas consideradas periféricas como la latina, fue compartido, por otra parte, por otras tendencias historiográficas e intelectuales surgidas en los países dominantes de la Europa contemporánea, situación que hoy en día está en proceso de reversión como efecto (beneficioso) de la globalización.

Una consecuencia práctica del distanciamiento persistente del "historiador más inteligente de Argentina" (según Romano) respecto de Annales, es que en su historia de la Edad Media europea publicada en dos tomos, La revolución burguesa en el mundo feudal (1967) y Crisis y orden en el mundofeudoburgués (1980), presta más atención a Italia y España que a Francia, centro del feudalismo medieval "clásico" según nos enseñó la historiografía francesa. Otra originalidad que le permitió, en general, marcar también distancias con el estructuralismo mecanicista de Sausurre, Levi-Strauss y Althusser, paradigma hegemónico en las ciencias sociales francesas de los años 60, al que se plegaron en exceso los Annales de Braudel, desviándose de los paradigmas fundadores. Se habría entendido mejor, sin duda, con la corriente marxista francesa de George Lefebvre, Albert Soboul, Michel Vovelle y Pierre Vilar, que siempre se consideró de alguna forma el ala izquierda de la escuela historiográfica fundada por Bloch y Febvre, pero tampoco hubo encuentro: bien por la no dedicación a los estudios medievales de sus miembros (en su mayoría, modernistas), bien porque el desinterés de Romero por los hegemónicos Annales arrastró al resto de los historiadores franceses.

El evidente paralelismo en cuanto a descubrimientos historiográficos entre los historiadores de Annales y José Luis Romero, no quiere decir que éste no aprenda de los avances de los franceses, por ejemplo, en lo relativo a la "historia de las mentalidades". Hasta los años 60, Romero trabaja con una idea de la historia de la

\footnotetext{
historia política" como historia social del poder; como ya vimos la redacción de la revista cambió el título por "Les problèmes de l'histoire sociale en Amérique latine", quitando la referencia a la denostada historia política y añadiendo el ámbito geográfico latino, dando a entender erróneamente que el artículo trata de la implantación de la historia social en América Latina, bajo la égida francesa, naturalmente; articulo y título original se reproducen en ROMERO, José Luis. Latinoamérica: situaciones e ideologías. Buenos Aires, 1967, p. 13-23; las citas están en p. 9, 16-17.

${ }^{100}$ Prólogo a José Luis Romero, Latinoamérica, las ciudades y las ideas, p. XIII.
} 


\section{Carlos BARROS. José Luis Romero y la Historia del siglo XXI.}

cultura en apariencia clásica, ya que la entendía como una "concepción integral de la historia". ${ }^{101}$ Utilizando para ello nociones que iban más allá de la vieja historia intelectual de autor y obra como: "espíritu burgués", "concepción de la vida", "ideales de vida", "pensamiento histórico-político". ${ }^{102}$ Hasta abrazar finalmente el concepto de "mentalidad" ${ }^{103}$ en La revolución burguesa en el mundo feudal (1967), a tiempo por tanto de ser un precursor -no leído, ciertamente, y menos aún reconocido- de los terceros Annales. Si definimos la 'mentalidad' por sus componentes principales (lo racional, lo emocional, el imaginario, el inconsciente y las prácticas ${ }^{104}$ ), encontramos en Bloch y Febvre, en los años 30-40, esa misma búsqueda de un término abarcador de toda la subjetividad mental, más allá de la conciencia clara y la ideología, que inicialmente no pasaba por utilizar el término "mentalidad" ${ }^{05}$ que conocían bien a través de la antropología y la psicología. Los segundos Annales promueven lo económico-social marginando lo mental, como se puede ver en la Méditerranée (1949) de Fernand Braudel, ${ }^{106} \mathrm{o}$ en la práctica desaparición del término "mentalité" en la revista Annales de los años 50-60. ${ }^{107}$

\footnotetext{
${ }^{101}$ Véase la nota 6.

${ }^{102}$ ROMERO, José Luis. ¿Quién es el burgués? y otros estudios de historia medieval. Buenos Aires, 1984, p. 17, 45, 108-109, 172.

${ }^{103}$ ACHA, Omar, op. cit., p. 101.

${ }^{104}$ BARROS, Carlos. Historia de las mentalidades: posibilidades actuales. Problemas actuales de la Historia, Salamanca, 1993, p. 49-67. Disponible en: www.h-debate.com/cbarros/spanish/ $\mathrm{hm} \_$posibilidades.htm.

${ }^{105}$ En 1924, Marc Bloch publica un trabajo paradigmático sobre mentalidades (religiosas), y sólo usa una vez la palabra "mentalités", junto con otros términos incluso más habituales como "habitudes de pensée", "idées collectives", "opinion commune", "représentations sociales", "représentations mentales". LE GOFF, Jacques. Préface à Les rois thaumaturges. Paris, 1983, p. XXVII-XXVIII; en 1939-1940, pasa algo parecido en La société féodale (trad. esp. Madrid, 1986) donde, en lugar de valerse del concepto de "mentalidad", titula el libro segundo "Condiciones de vida y atmósfera mental", y sus capítulos II y III, "Formas de sentir y de pensar" y "La memoria colectiva"; en una carta del 8 de mayo de 1942, Bloch confiesa incluso a Febvre que "mentalité" le parece un "terme médiocre" que se "prête à certains équivoques", BLOCH, Marc; FEBVRE, Lucien. Correspondance. III. Les Annales en crises, 1938-1943. Paris, 2003, p. 197; por otro lado, Lucien Febvre que nos dejó valiosos trabajos metodológicos sobre el nuevo enfoque que después llamaremos "historia de las mentalidades", maneja más bien "utillaje mental", "sensibilidades" y otros términos vecinos, "Une vue d'ensemble. Histoire et psychologie (1938), "La sensibilité et l'histoire. Comment reconstituer la vie affective d'autrefois? (1941), republicados en Combats pour l'histoire, Paris, 1953 (eliminados de la edición española de Ariel, Barcelona, 1970).

${ }^{106}$ Posteriormente, Fernand Braudel llega a hacer una historia moderna de la vida cotidiana desde un ángulo económico, en Civilisation matérielle, économie et capitalisme, XVe-XVIIIe siècle, Paris, 1979; el estudio de la vida cotidiana es un tema de origen antropológico que sólo años después (19851987) George Duby introduce como "historia de la vida privada" en el campo de las mentalidades, añadiendo la sensibilidad y las representaciones mentales a la vida material, tratada por Braudel. ${ }^{107}$ Véase la nota 114.
} 
Un artículo de George Duby de 1961 sobre la "Histoire des mentalités" trae de nuevo a la memoria historiográfica el tema de forma definida ${ }^{108}$, sin demasiados efectos, tal vez por el carácter "externo" del renombrado historiador a la revista Annales y sus instituciones, todavía bajo el control braudeliano. Será más efectivo trece años después, otro artículo, también de orden metodológico-historiográfico de Jacques Le Goff publicado en Faire l'histoire ${ }^{109}$ (primera gran obra colectiva de los Annales post-Braudel) en 1974 (siendo presidente de la VI sección de la EPHE), donde se lanza definitivamente la "historia de las mentalidades ${ }^{110}$, pese a su título ambiguo y las dudas heredadas de los fundadores ${ }^{111}$, como banderín de enganche de los terceros Annales.

En ese momento, Romero llevaba años manejando, paralelamente a Duby y Le Goff, incitado como ellos por los avances iniciales de Bloch ${ }^{112}$, un concepto claro de mentalidad en sus trabajos sobre la Edad Media europea. No tengo duda de que Romero, como historiador de las mentalidades, estuvo influido por sus lecturas previas de los fundadores de Annales. ${ }^{113}$ Sin que resulte afectado por "edad oscura" de Braudel (para la historia de las mentalidades), durante la cual Annales admite con todo algunas referencias aisladas al término: un raro artículo con "mentalidad" en el título se publica en 1949, y siguen siete más durante las dos décadas de los años 50 y $60 .{ }^{114}$

\footnotetext{
${ }^{108}$ DUBY, George. Histoire desmentalités. L'histoireetsesméthodes. París, 1961 (no fuetraducidoal español).

${ }^{109}$ LE GOFF, Jacques. Las mentalidades: una historia ambigua. Hacer la Historia, III, Barcelona, 1980 (París, 1974).

${ }^{110}$ Le Goff viene incluyendo las mentalidades desde los años 60, en contraste con Braudel, en sus investigaciones sobre la Edad Media (véase la nota 113).

${ }^{111}$ Véase la nota 113.

${ }^{112}$ Véase la nota 105

${ }^{113}$ Como medievalista, Romero sigue, desde las primeras ediciones en francés, las obras de investigación económico-social de Bloch; en La revolución burguesa en el mundo feudal (1967) cita excepcionalmente -lo que prueba que su reconocimiento de 1953 es sincero- seis veces, a pié de página, al fundador de Annales (p. 88, 89, 101, 133, 268 y 358); interesa la primera mención a La société féodale (Les Éditions Albin Michel, Collection 'L'évolution de l'Humanité', tomes XXXIV et XXXIVbis, Paris, 1939-1940, 1949), donde, fiel a su estilo diferenciador, explica que lo que Bloch llama primera y segunda edad feudal, él denomina periodo feudal y feudoburgués (p. 88 n. 8); no cabe dudar, pues, que leyó en el tomo I de "La sociedad feudal" la parte de las mentalidades, que Bloch relaciona con las "condiciones materiales" de vida, interconexión que Annales abandonará en los años 70, pese al magisterio de Le Goff, quien desde los años 60, siguiendo el enfoque global de Bloch, integra las mentalidades con el resto de la historia medieval en La civilisation de l'Occident médiéval. Paris, Arthaud, 1965.

${ }^{114}$ SILBERT, Albert. Ouvrages sur la mentalité des Américains. Annales, 1949, vol. 4, num. 2, p. 248-251 (trata de los EE. UU.); aparecen otros siete más sobre mentalidades en los años 50-60 hasta el artículo definitivo de Le Goff en Faire l'histoire (1974), después crecen exponencialmente hasta un total de 1.752 referencias hasta 2002.
} 


\section{Carlos BARROS. José Luis Romero y la Historia del siglo XXI.}

De este ir y venir entre lecturas y reflexiones propias, surge la peculiar historia de las mentalidades de Romero, que no deja de lado el enfoque global, a diferencia de los franceses, cuya historia de las mentalidades se desarrolló, en los años 70 y 80, cada vez más separada del resto de la historia, sobre todo de la historia social. ${ }^{115}$ Por el contrario, el historiador "periférico" incluye la mentalidad en sus investigaciones históricas de conjunto junto - entrelazadamente - con los aspectos social y económico, político y cultural, con mayor fidelidad por tanto al proyecto original de Bloch y Febvre (si bien eso a Romero, la verdad sea dicha, ni le movía, ni le preocupaba). Así analiza nuestro historiador pionero en su gran obra de los años 60, La revolución burguesa en el mundo feudal, las mentalidades señorial, religiosa y burguesa, así como el cambio de mentalidades medievales que provoca la burguesía a partir de la Plena Edad Media, cuyo estudio pretendía prolongar hasta los tiempos contemporáneos. ${ }^{116}$ Dejando para su continuación bajomedieval, Crisis y orden en el mundo feudoburgués, publicada póstumamente, el análisis de la "mentalidad popular" y el "conflicto de las mentalidades" en el tardo medioevo, previsto para una "cuarta parte" que no llegó a redactar. ${ }^{17}$ Es evidente que Romero hace lo que hemos llamado, en los años 80 , una "historia social de las mentalidades" ${ }^{118}$ : no olvida su marxismo cuando investiga la subjetividad humana y mental, otra prueba más de la coherencia entre sus investigaciones históricas concretas y un marxismo que hace hincapié en las "ideas", antidogmático y no estructuralista, "dialéctico múltiple", humanista.

Así y todo, no toda la gente de Annales trató de la misma manera a José Luis Romero, inteligente historiador pero argentino: las excepciones son el ya citado Ruggiero Romano (él mismo latino-europeo de origen), en la época de Braudel, y sobre todo Jacques Le Goff, el representante más genuino de los terceros Annales. ${ }^{119}$ Quien, tres años después de publicarse La revolución burguesa en el

\footnotetext{
${ }^{115}$ BARROS, Carlos. Historia de las mentalidades, historia social. Temas Medievales, Buenos Aires, $\mathrm{n}^{\circ}$ 2, 1992, p. 205-230. Disponible en: www.h-debate.com/cbarros/spanish/hm_historia_social. htm; La contribución de los terceros Annales y la historia de las mentalidades. 1969-1989. La otra historia: sociedad, cultura y mentalidades, Bilbao, 1993, p. 87-118. Disponible en: www.hdebate.com/cbarros/spanish/contribucion.htm.

${ }^{116}$ Su interés por la revolución burguesa tenía para Romero, además de su intrínseco interés historiográfico, una dimensión comprometida con su lucha por el socialismo, (véase la referencia de la nota 80$)$.

${ }^{117}$ ROMERO, Luis Alberto. Prólogo a Crisis y orden en el mundo feudo burgués. México, 1980, p. 9-10.

${ }^{118}$ Véanse las referencias bibliográficas de las notas 104, 115.

${ }^{119}$ Representatividad de Jacques Le Goff que no todo el mundo, dentro y fuera de Francia, le reconocía, lo que plantea una duda que algunos nos hemos planteado: Le Goff no tuvo tal vez la posibilidad real de orientar en los años 70 la escuela de Annales como él hubiese deseado,
} 
mundo feudal, ejecutado ya el giro radical que puso fin a los Annales braudelianos, incluye una cita de la obra de Romero en un artículo de historia medieval en Annales. ${ }^{120} \mathrm{Si}$ bien será, ya jubilado, fuera de cualquier responsabilidad en boulevard Raspail y desaparecida Annales como corriente colectiva ${ }^{121}$, cuando conoce más textos de Romero y redacta una presentación realmente elogiosa para la segunda edición (2003) de Crisis y orden en el mundo feudoburgués. ${ }^{122}$ Dice el gran Le Goff de José Luis Romero que "fue un gran medievalista, uno de los que revolucionaron, que renovaron profundamente, la imagen de la Edad Media" 123 , y que su obra inconclusa "permanece como uno de los monumentos más impresionantes y más notables de la historiografía del siglo XX". ${ }^{24}$ Siendo importante este reconocimiento formal (viniendo de un francés), lo es más ${ }^{125}$ que se valore retrospectivamente el vanguardismo, la creatividad y la autonomía intelectual de Romero, sea anticipándose a Annales, sea triunfando justamente donde más fracasó la escuela francesa.

Escribe, por ejemplo, Jacques Le Goff en su prólogo que "José Luis Romero volvió a encontrar en los textos medievales la concepción de Georges Dumézil, que tal vez no había leído, de una idea indoeuropea del esquema de la sociedad tripartita (oratores, bellatores, laboratores), casi al mismo tiempo en que Jean Batany, Georges Duby y yo mismo la descubríamos". ${ }^{126}$ En realidad, el descubrimiento del sistema trifuncional por parte de Romero es anterior a Dumézil

manteniendo la "historia total" y abriéndose bilateralmente a otras historiografías, generando unos terceros Annales más globales que hubieran facilitado sin duda una mejor adaptación de los historiadores franceses a la mundialización en curso.

${ }^{120}$ Véase la nota 44

${ }^{121}$ BARROS, Carlos. La Escuela de los 'Annales' y la historia que viene. La historia que se fue, Suplemento Cultural del Diario de Sevilla, $n^{\circ}$ 99, 18 de enero de 2001. Disponible en: www.hdebate.com/cbarros/spanish/articulos/historiografia_inmediata/escueladeannales.htm.

${ }^{122}$ Véase la nota 23.

${ }^{123}$ Crisis y orden en el mundo feudoburgués, Buenos Aires, 2003, p. VII.

${ }^{124}$ Idem, Ibidem, p. XI.

${ }^{125}$ Por lo que pueda tener de autocrítica del dernier annaliste: para nosotros, Jacques Le Goff es el historiador actual más relevante que permanece todavía fiel, de alguna manera, en Francia a los presupuestos historiográficos y cívicos de la escuela que fundaron Marc Bloch y Lucien Febvre en 1929; otros que integraron en el pasado las filas de Annales se consideran hoy solamente parte de una historiographie française que integra su pasado annaliste, pero no lo reivindica públicamente.

${ }^{126}$ Crisis y orden en el mundo feudoburgués. Buenos Aires, 2003, p. VIII. 


\section{Carlos BARROS. José Luis Romero y la Historia del siglo XXI.}

$\left(1958^{127}\right)$, Batany $\left(1963^{128}\right)$, Le Goff $\left(1968^{129}\right)$ y Duby $\left(1973^{130}\right)$, ya que el artículo que llamó la atención a Le Goff, El espiritu burgués y la crisis bajomedieval, fue originalmente escrito y publicado en Montevideo por Romero tan pronto como en $1950 .{ }^{131}$ Texto donde concluye, con espíritu anticipador, que "dentro de la concepción organicista de la sociedad que prevalece durante la Edad Media, se admitía que la integraban tres brazos... Defensores, oradores y labradores". ${ }^{132}$ Concepción cuyo lejano origen sitúa Romero en la Política de Aristóteles e infiere, para el periodo medieval, de la conocida frase del francés Adalberto de Laon (siglo XI), seguida de una rica serie de textos españoles del siglo XIII al siglo XV (Alfonso X, Ramón Llull, Juan Manuel, Diez de Games), terminando con el italiano Marsilio de Padua, lo que le permite enlazar con el surgimiento del "subgrupo" de los burgueses del tercer estado de los labradores. ${ }^{133}$

La difusión de la mentalidad trifuncional en el medievalismo internacional, tiene lugar, 28 años después del descubrimiento de Romero ${ }^{134}$, gracias a la obra crucial de Georges Duby, Les trois ordres ou l'imaginaire du féodalisme (Paris, 1978), sobre fuentes exclusivamente francesas, por supuesto. Constituyó este libro uno de los grandes éxitos de las mentalidades de los terceros Annales, aunque tuvo poco seguimiento investigativo. Difusión que muestra, en cualquier caso, la importancia ${ }^{135}$ de estar respaldado por una corriente historiográfica generada en este

${ }^{127}$ DUMÉZIL, Georges. L'Idéologie tripartite des Indo-Européens, Paris, 1958; se trata de la obra que difunde en las ciencias humanas francesas la idea de la trifuncionalidad, que el filólogo francés venía usando en sus investigaciones antropológicas.

${ }^{128}$ BATANY, Jean. Des 'trois fonctions' á 'trois états'. Annales, vol. XVIII, 1963, p. 933-938.

${ }^{129}$ LE GOFF, Jacques. Note sur société tripartie, idéologie monarchique et renouveau économique dans chrétientié du IXe au XIIe siècle. L'Europe aux IXe-XIe siècle (Colloque 1965), Varsovia, 1968, p. 63-72.

${ }^{130}$ DUBY, Georges. Aux origines d'une système de classification sociale. Mélanges à l'honneur de Fernand Braudel, Paris, 1973, tome II, p. 183-188.

${ }^{131}$ Pensamos que Le Goff conoce el texto sobre el espíritu burgués hacia 2003 a través de la recopilación editada por la UBA, en 1961, como Ensayos sobre la burguesía medieval. Ensayos de Historia Social (Crisis y orden en el mundo feudoburgués, p. VIII)

${ }^{132}$ ROMERO, José Luis. El espíritu burgués y la crisis bajomedieval. Revista de la Facultad de Humanidades y Ciencias, $\mathrm{n}^{\circ}$ 6, Montevideo, abril de 1950; reproducido también en ¿Quién es el burgués?, y otros estudios de historia medieval, Buenos Aires, 1984, p. 18-19.

${ }^{133}$ Idem, Ibidem.

${ }^{134}$ Sobra decir que los historiadores franceses seguidores de Georges Dumézil (1898-1986) no conocieron ni podían conocer el texto de Romero: en general, no leían español y cierta mentalidad "imperial", "legitimada" en parte por la rica tradición francesa, dificultaba cualquier acercamiento libre de prejuicios a la "periferia" latina.

${ }^{135}$ Para un historiador con ambiciones historiográficas, además de tener talento, que a Duby le sobraba -al igual que a Romero -, lo importante era estar en el lugar y en el momento adecuado. 
caso desde un país que, en el pasado siglo, irradió internacionalmente con enorme efectividad su idioma, su cultura y grandeur, con el apoyo ejemplar del Estado.

Con este arranque de honestidad y sinceridad que muy pocos historiadores franceses serían capaces de emular, incluso hoy (a toro pasado), Jacques Le Goff reconoce en José Luis Romero un "pionero de las representaciones y del imaginario", puesto que, según vimos, el argentino descubre historiográficamente lo mental en 1950 (dice Le Goff en 1961, porque manejó una edición posterior ${ }^{136}$ ), cuando publica su trabajo sobre el "espíritu" de la burguesía medieval. ${ }^{137} \mathrm{Admi}-$ rando, por lo demás, su "visión optimista de la historia"138, vinculada -añadimos nosotros- con sus convicciones profundas de socialista ilustrado. Pero donde el reconocimiento, en 2003, del prologuista parisino es más autocrítico, generoso y historiográficamente significativo es cuando afirma que José Luis Romero triunfó historiográficamente en algo muy importante que Annales pretendió y no consiguió: hacer una "historia total" ${ }^{139}$ Confesión que explica lo que decíamos supra sobre cómo la imposible integración de Romero en los Annales de Braudel ${ }^{140}$, evitó que reprodujera individualmente sus defectos y fracasos, haciendo posible por consiguiente, desde finales del siglo XX, un interés renovado, nacional e internacional, por su obra y vida, inversamente proporcional al agotamiento de las escuelas historiográficas que pudieron servir de referencia crítica, e iconoclasta, en su difícil andadura para nada devota.

\section{Romero y la historia que viene}

A modo de resumen, vamos a definir ocho aportaciones vitales de José Luis Romero como historiador avanzado del siglo XX al nuevo consenso (paradigma) sobre la escritura de la historia, en el siglo XXI, que estamos construyendo otros que venimos de parecidas proximidades e influencias históricas e historiográficas, junto con nuevas generaciones de historiadores que quieren afrontar los desafíos del presente, aprendiendo de los errores del pasado, procurando así una nueva primavera para la historia que nos toca escribir y vivir.

\footnotetext{
${ }^{136}$ Véase la nota 131.

${ }^{137}$ Crisis y orden en el mundo feudoburgués, $\mathrm{p}$. X-XI.

${ }^{138}$ Idem, Ibidem.

${ }^{139} \mathrm{Idem}$, Ibidem, p. IX.

${ }^{140}$ Los terceros Annales (1969-1989) llegaron tarde para Romero, tampoco cambiaron la mentalidad jerárquica centro-periferia de la historiografía francesa.
} 


\section{Nueva historia global}

Ya lo dijo Jacques Le Goff en su reconocimiento autocrítico sobre Romero de 2003: "Su obra es el más bello ejemplo que conozco de este historia global preconizada y jamás realizada en su totalidad por los historiadores franceses de Annales". ${ }^{141}$ Tres son los rasgos de la obra de Romero que interesan, en nuestra opinión, para una nueva historia "total" que, al igual que Le Goff, preferimos llamar "global" superando el tono idealista -utópico en el sentido de imposible- del concepto de "totalidad" utilizado por las vanguardias historiográficas del siglo pasado:

a) Su constante huida de la historia fragmentada, especializada, haciendo converger géneros y temas de investigación (lo que hemos llamado "historia mixta como historia global"142 o reemplazando como objeto de investigación el hecho histórico por la vida histórica. ${ }^{143}$

b) Romero buscó siempre, en verdad, la interrelación de las cosas, aconsejándole a Ruggiero: "Romano, le recomiendo, usted debe mostrar, subrayar, el entronque que existe entre los distintos problemas", quien tal vez no conocía la palabra 'entronque' (ni había aprendido en París lo que le quería decir historiográficamente) pero concluye: "No se hace historia sin imbricación, conexión, intercambio de problemas, o sucesivas convergencias hacia un centro. De esto José Luis Romero ha sido un incomparable Maestro". ${ }^{144}$

c) No era un estructuralista al uso, su objetivo era captar globalmente el cambio histórico. El ángulo metodológico elegido para entender la vida histórica medieval fue el conflicto burguesía / nobleza feudal, aun sabiendo que la contradicción señores / campesinos provoca la crisis del feudalismo, que -añade-resulta acelerada y profundizada por la burguesía urbana como factor exógeno ${ }^{145}$ (un ejemplo de lo que entendía Romero como entronque o dialéctica multilate-

\footnotetext{
${ }^{141}$ Crisis y orden en el mundo feudoburgués. Buenos Aires, 2003, p. IX.

${ }^{142}$ BARROS, Carlos. La historia mixta como una historia global. Enfoques. Revista de la Universidad Adventista del Plata, Argentina, año XVIII, n ${ }^{\circ} 1-2,2006$, p. 91-118. Disponible en: http:// redalyc.uaemex.mx/redalyc/src/inicio/IndArtRev.jsp?iCveNumRev=6913\&iCveEntRev=259\& institucion; con este título y enfoque hemos organizado, en 2004, con la participación de Ciro F. Cardoso, Carlos Martínez Shaw y Raquel García Bouzas, un apartado temático en el último congreso de Historia a Debate. Historia a debate. III. Historiografía global. BARROS, Carlos. (Ed.). Santiago, 2009, p. 39-71.

${ }^{143}$ Véase la nota 89.

${ }^{144}$ ¿Quién es el burgués? y otros estudios de historia medieval, p. 14.

${ }^{145}$ Crisis y orden en el mundo feudoburgués. Mexico, 1980, p. 102-103.
} 
ral). Justamente, lo característico de la nueva historia global que propugnamos - desde $\mathrm{HaD}$ - es definir hipótesis de partida que permitan obtener aproximaciones globales, dejando atrás eso de "la historia total como un horizonte utópico" al que nunca se llega. La opción de Romero es investigar globalmente la Edad Media (siglos XI-XV) empleando como hilo conductor, y punto de vista, la burguesía y las ciudades (siguiendo a Pirenne), lo que no excluye - más bien sugiere - otros enfoques concurrentes, como el aplicado por la tradición historiográfica marxista que el autor conoce, valora y logra mejorar.

\section{Ejemplo de futuro: una historia pensada}

Todavía hoy bastantes colegas siguen reduciendo el oficio de historiador al documentalismo (que decía Romero), a conocer el pasado "tal como fue" a través de las fuentes, condición desde luego necesaria pero insuficiente para una historia realmente profesional. Por ello recordar a Romero y su modo de trabajar, refuerza nuestra idea ${ }^{146}$ de que para ser buen historiador hay que reflexionar sobre metodología, historiografía, teoría de la historia, relación con la sociedad...

Sobre metodología véase la compilación de artículos de Romero editada por su hijo Luis Alberto como La vida histórica (Buenos Aires, 1988). Sobre historiografía lo más significativo sea tal vez el libro Maquiavelo historiador (1943), en cuya introducción a la segunda edición (1970) José Luis Romero lamenta que el "análisis historiográfico" siga siendo un "género de investigación.... deficientemente discriminado". ${ }^{147}$ Celebrando como una excepción que, a la hora de investigar historiográficamente a Maquiavelo, además de inferir datos de sus obras históricas, se pueda completar éstos con los extraídos de "una actividad pareja en el campo teórico". ${ }^{148}$ Invitándonos, en suma, a cultivar ambos campos, tanto a la hora de producir historia como de investigar a historiadores. Considerando muy necesario, pues, hacer la historia "de cómo se ha historiado un tema... para desarmar las subjetividades que hayan podido incurrir" los propios historiadores. Mostrando una vez más su sorpresa, en 1976, porque la "historia de la historiografía" como tipo de conocimiento "no ha conseguido la acogida y el interés de la gente, cuando es tan seductor". ${ }^{149}$ Sobre teoría de la historia, ya

\footnotetext{
${ }^{146}$ Véase el punto 13 de La historia que viene. Historia a debate. I. Pasado y futuro. Santiago, 1995, p. 95-117. Disponible en: www.h-debate.com/cbarros/spanish/historia_que\%20viene.htm. ${ }^{147}$ ROMERO, José Luis. Maquiavelo historiador. Buenos Aires, 1986 ( $3^{\text {a }}$ edición), p. 18.

${ }^{148}$ Idem, Ibidem. p. 21.

${ }^{149}$ LUNA, Félix, op.cit., p. 72; la respuesta está, sin lugar a dudas, en la prolongada pervivencia del positivismo y su "idolatría de las fuentes".
} 


\section{Carlos BARROS. José Luis Romero y la Historia del siglo XXI.}

hablamos de su gran proyecto inconcluso, Teoría general de la vida histórica: "una investigación que nunca se ha hecho de una manera definitiva"150, declaró Romero a Félix Luna un año antes de morir, después de afirmar la necesidad y la posibilidad de superar dialécticamente al propio Marx. ${ }^{151}$ Tarea abandonada entonces por otros, y hoy todavía pendiente: por la escasez en el siglo XX de historiadores annalistes y/o marxistas con el interés, la ambición y formación teórica de José Luis Romero; la evolución de la filosofía de la historia al margen de los historiadores profesionales ${ }^{152}$; y la crisis intelectual del marxismo iniciada justamente a finales de los años 70, en la Europa latina y otros lugares, profundizada para muchos de forma irreversible a partir de 1989.

Según nuestro criterio, sin embargo, acertó José Luis Romero cuando se planteó inspirarse en el marxismo para superar al marxismo, no en vano fue la filosofía de la historia más influyente en el siglo XX, también entre los nuevos historiadores. Debería ser, por consiguiente, obligatorio punto de partida para repensar crítica y autocríticamente la teoría de la historia en el siglo XXI; no sólo el papel las ideas (junto con la base material) o la multiplicidad dialéctica y global que preocupaban a Romero, también en lo relativo a la "sucesión de modos de producción", cuyo fracaso -que el historiador argentino no llegó a conocer plenamente- puso en evidencia la "inesperada" transición, de 1989 en adelante, del socialismo soviético al capitalismo, dando vía libre, de un lado, a filosofías occidentales de la historia pronto desmentidas desbordadas por la aceleración histórica (posmodernidad, Fukuyama, Huntington) y, por el otro, a los rebrotes violentos de un fundamentalismo islámico con afán de gobierno global (califato universal). Globalización sin rumbo y retorno del irracionalismo que nos obligan a seguir reflexionando sobre la evolución objetiva y subjetiva de la humanidad, sin poder renunciar a que la razón guie la relación pasado/presente/futuro, sabiendo ahora como sabemos que no existe un final inevitable, que todo depende de nosotros.

\footnotetext{
${ }^{150}$ Idem, Ibidem, p. 128.

${ }^{151}$ Idem, Ibidem, p. 92-93.

${ }^{152}$ Véase, en sentido contrario, PINTOS PEÑARANDA, María Luz. Sobre la utilidad de la Filosofía para la Historia. Propuesta de distinción y de confluencia. Historia a debate. III. Problemas de historiografia. Santiago, 2000, p. 209-223; Desde la interdisciplinaridad, modelos de "actitud" crítica y de compromiso ante la historia. La convergencia entre Historia a Debate y la Fenomenología. Historia a debate. III. Historiografía global, Santiago, Historia a Debate, 2009. p. 163-173.
} 


\section{Historia comprometida}

El modelo (parcial) de Romero es Maquiavelo como historiador, admiraba sobre todo su "pleno compromiso" con su tiempo. ${ }^{153}$ Consecuentemente el profesor Romero defendió como dirigente político la necesidad de combinar teoría y práctica ${ }^{154}$, de basar las políticas socialistas en "una investigación profunda de nuestra realidad", según escribía en su artículo "Estudio y militancia" (Futuro socialista, $\left.\mathrm{n}^{\mathrm{o}} 1,1958\right) .{ }^{155}$ Doble faceta de José Luis Romero que conocemos (junto con los prólogos de Luis Alberto a sus obras) gracias al libro de Omar Acha, La trama profunda. Historia y vida en José Luis Romero (Buenos Aires, El cielo por asalto, 2005), muy a considerar cuando lo habitual es que se nos ofrezcan visiones exclusivamente académicas de los historiadores biografiados. Ciertamente no suele haber que decir vitalmente de otros historiadores académicos, salvo situar autor y obra en el contexto socio-político, pero no es el caso que nos ocupa, ya que el sujeto historiador quiso ser también sujeto histórico. Es por ello que Romero, a menudo, no distingue su objeto de historiador de su ideología como ciudadano: "soy un socialista reformista, que hoy es, a mi juicio, la máxima expresión de la vivencia del proceso histórico" ${ }^{156}$, a cuya investigación dedicó buena parte de su vida. Un socialismo de base ilustrada que ilumina su obra, tanto historiográfica como política: "Yo no creo que el hombre sea siempre igual. En esto sí soy un optimista constitucional y filosófico. Yo creo que el hombre es cada vez mejor". ${ }^{157}$ Visión optimista de la historia - que tanto admiraba Le Goff, como vimos ${ }^{158}$ - y que Romero también aplicó a sus estudios medievales que supo relacionar, en la larga duración, con la historia contemporánea y actual de Argentina y América Latina. Llegó a decir que "yo no conozco más grandes historiadores que los comprometidos, de alguna manera". ${ }^{159}$ Ponía en práctica -a veces con mayor consecuencia- una relación pasado / presente parecida a la defendida por la historiografía marxista y los primeros Annales: "es el presente el que le pregunta al pasado. Y si no, no hay historia". ${ }^{160} \mathrm{Cara}$ al futuro, pese a su vinculación a la Ilustración y al marxismo fundacional (otra

\footnotetext{
${ }^{153}$ Maquiavelo historiador, p. 9.

${ }^{154}$ Se le criticaba acerbamente por ello (véase la nota 18 ).

${ }^{155}$ ACHA, Omar, op. cit., p. 57.

${ }^{156}$ LUNA, Félix, op.cit., p. 143.

${ }^{157}$ Idem, Ibidem, p. 107.

${ }^{158}$ Véase la cita de la nota 138.

${ }^{159}$ LUNA, Félix, op.cit., p. 22.

${ }^{160}$ Idem, Ibidem, p. 21.
} 
vez autonomía de criterio), se opone tempranamente a cualquier concepción finalista de la historia: "los objetivos que el hombre persigue no los veo en la línea del finalismo metafísico como se entiende esto en el sentido teológico o filosófico. Sin perjuicio de que haya quien pretende imponer ese finalismo, creo que hay más bien objetivos de corto plazo, de mediano plazo, de largo plazo, establecidos, impuestos, inventados, creados por el hombre, que resultan tener después una cierta coherencia". ${ }^{161}$ Posición anticipatoria sobre el debate de los fines de la historia que hemos recogido como punto de consenso (número XIV) en el Manifiesto historiográfico de HaD (2001). Porque Romero también se preocupaba por el futuro (abandonado hoy por tantos, cuando más falta hace), atreviéndose a incursionar en la prospectiva histórica. Como cuando considera irreversible, en la Argentina peronista, la "toma de conciencia social por parte de las clases populares", lanzando "una previsión a largo plazo": “Argentina será un país en el cual las clases populares tengan un papel decisivo". ${ }^{162}$ De alguna manera fue así, si atendemos al peso histórico de las masas peronistas. Y tal vez lo sea todavía más en países que están viviendo en el nuevo siglo un importante proceso de concienciación popular como Venezuela, Bolivia y Ecuador.

\section{Contra el espíritu de especialidad (Lucien Febure)}

Una enseñanza de Romero para jóvenes historiadores de este siglo que quieran seguir los mejores ejemplos pasados es su difícil etiquetación, dentro de la historia académica. En tiempos de hiperespecialización, fragmentación y no poco corporativismo historiográfico, José Luis Romero es referencia saludable, y muy necesaria. Ciertamente se tenía por medievalista, lo que nos place, pero fijémonos como lo argumenta ante Félix Luna, cuanto le pregunta: "Usted es un medievalista. Le pregunto si su especialidad le sirve para entender mejor los procesos históricos argentinos". Respuesta: "Tengo miedo de contestarle lo que pienso, porque me inclino a creer que sólo los medievalistas los entendemos bien", sobre todo si estudian como él -que analizaba Argentina como parte de la historia occidental, pese al eurocentrismo dominante- la historia de la burguesía. ${ }^{163} \mathrm{El}$ caso es que Romero era un medievalista atípico: estudió asimismo historia antigua, moderna, contemporánea y actual, fue un "historiador total", tanto temporal como espacialmente, a lo que tenemos que añadir su compromiso

\footnotetext{
${ }^{161}$ Idem, Ibidem, p. 100-101.

${ }^{162}$ Idem, Ibidem, p. 113.

${ }^{163} \mathrm{Idem}$, Ibidem, p. 58.
} 
y una dedicación a la metodología, la historiografía y la teoría de la historia, que aportó coherencia a sus dimensiones varias como historiador (y persona). Práctica global y diversa que le quitó ciertamente tiempo para terminar tal o cual proyecto, pero hizo posible que, tres décadas después, estamos aquí proponiéndolo como precedente de nuevo paradigma global, siendo como es, la segmentación interna de la disciplina, el mayor problema historiográfico a resolver en este siglo XXI.

\section{El universalismo de Romero}

Un rasgo asimismo heterodoxo de José Luis Romero, derivado de los puntos anteriores, fue la orientación universal de su obra historiográfica, y también vital. Recorrió más de doscientas ciudades del mundo, fue un activo viajante-historiador que publicaba crónicas en revistas no académicas y no dejaba de sacar notas para su gran historia mundial de las burguesías y ciudades occidentales. ${ }^{164}$ Internacionalismo muy apropiado en tiempos de una globalización que ha generado una valorada World History como nueva historia global ${ }^{165}$ de la cual también fue Romero precursor ignorado. Supo combinar las historias de Argentina, América Latina y Europa, practicando un eurocentrismo al revés: en lugar de ver el mundo desde Europa, veía Europa desde el mundo, como sólo se podía hacer desde una de las ciudades latinoamericanas más internacionales: Buenos Aires. Ya dijimos que Romero fue un latinoamericano medievalista por vocación, pero nada corporativo: hizo además historia antigua, moderna y contemporánea, nada histórico le resultó ajeno. Unos verán en ello dispersión, académicamente poco "apreciada" - al menos en Europa - pero historiográficamente excepcional, nos acerca al historiador global que fue Romero: lo echamos de menos en la presente sociedad global de información.

\section{Historia inmediata}

Su concepción global de la historia, escaso academicismo y elevado compromiso ético, social y político, llevó a Romero a desplazar hasta la actualidad su mirada de historiador, desde Las ideas políticas en Argentina (1946) hasta Latinoamérica: las ciudades y las ideas (1976). Del primer trabajo comentó en

\footnotetext{
${ }^{164}$ Resultado de ello fue su monumental La ciudad occidental. Culturas urbanas en Europa y América, Buenos Aires, 2009; véase también ACHA, Omar, op. cit., p. 147-167.

${ }^{165}$ BARROS, Carlos. Primeras conclusiones del III Congreso Internacional Historia a Debate (14-18 de Julio de 2004). Historia a debate. I. Reconstrucción, Santiago, Historia a Debate, 2009, p. 73. Disponible en: www.h-debate.com/cbarros/spanish/articulos/nuevo_paradigma/conclusiones.../ primeras\%20conclusiones.htm.
} 
1976. "Yo he tratado de ser lo más objetivo posible, pero como soy un hombre de partido y mis opiniones políticas son tales y cuales, las declaro para que el lector las tenga presentes". ${ }^{166}$ Sinceridad que hace sobresalir a nuestro historiador de otros colegas, de ayer y de hoy, que se escudan en un caduco concepto hiperobjetivista de ciencia ${ }^{167}$ dejando, en ocasiones inconscientemente, que sus subjetividades influyan bajo cuerda en sus investigaciones, dificultando el trabajo del historiógrafo futuro. La reconocida subjetividad objetiva de Romero le conduce, decíamos, a una historia menos mediata, más reciente, actual, que reivindica ante Félix Luna: "Yo creo que hay que hacer la historia contemporánea" (en sentido literal, no académico, remarcamos), al tiempo que insiste en la "educación para la objetividad" y el uso de las fuentes orales (rehabilitando a Herodoto $^{168}$ ) a fin de captar directamente los sujetos en acción. Teniendo como referente de nuevo a Maquiavelo, antes por su compromiso político ahora por su rigor al estudiar la realidad inmediata ("la historia reciente de Florencia e Italia"), con fuentes y datos ${ }^{169}$, criticándolo por no aplicar también un enfoque empírico al analizar "la historia antigua", los "procesos históricos remotos", dejándose llevar por esquemas preconcebidos, derivados de un "idealismo racionalista", de una "filosofía de la historia dogmática", que le "constriñe a deformar" los hechos, frustrando así sus "dotes innegables de historiador". ${ }^{170}$ Dotes de historiador (según criterios positivistas, se entiende) que reconocía paradójicamente en sus trabajos sobre la historia inmediata de la Florencia y la Italia tardomedievales a través de crónicas y otras fuentes, incluidas sus vivencias. El temor de Romero era más bien el contrario. Le inquietaba no ser suficientemente "documentalista" como medievalista y tenía mala conciencia -como si ello no fuese también normal por su subjetividad política al hacer -con el rigor habitual- Historia Inmediata sobre Argentina. Con pesar su amigo Ruggiero reconoció que "su independencia de espíritu lo llevaba muchas veces a ciertas contradicciones", negándose a hacerle la "autopsia", por ejemplo, de su "parte griega, la romana, la medieval, la americana, la argentina", o de su definición compleja del ser historiador como "oficio" y como "pasión". ${ }^{171}$ Realmente no era fácil, hace tres o cuatro décadas,

\footnotetext{
${ }^{166}$ LUNA, Félix, op. cit., p. 86.

${ }^{167}$ Véase una crítica actualizada en BARROS, Carlos. Por un nuevo concepto de la historia como ciencia. 2005. Disponible en: http://www.youtube.com/user/HistoriaDebate.

${ }^{168}$ LUNA, Félix, op. cit., p. 84-88.

${ }^{169}$ Maquiavelo historiador, p. 97, 104-108.

${ }^{170}$ Idem, Ibidem, p. $96,108$.

${ }^{171}$ ¿Quién es el burgués? y otros estudios de historia medieval, p. 9-10.
} 
entrever avant la lettre el historiador global que era Romero. El mismo, que iba más allá del puro "documentalismo", quería ser "normal". Procuraba ciertamente el rigor empírico pero no dejaba de ser teórico. Se decía medievalista, pero hacía cosas que no hacían ni estudiaban los medievalistas comunes. Cultivaba la Historia Inmediata, confesando su ideología social-democrática al tiempo que define su línea de trabajo historiográfico sobre la actualidad no "exactamente la de la militancia, sino la de la preocupación por las cosas de mi tiempo, en mi país y en el mundo", añadiendo curiosamente que no es "el campo estrictamente intelectual de mis intereses", concluyendo: "Yo digo siempre que soy un medievalista" ${ }^{172}$ En fin, vacilaciones y paradojas de un historiador adelantado a su tiempo, en el contexto de un siglo XX en que ni Annales ni la historiografía académica marxista, entendían realmente el presente como objeto de investigación histórica en sí mismo.

\section{Historiador individual, tendencias colectivas}

Hemos analizado en detalle la complicada relación de José Luis Romero con el marxismo y Annales, para entender mejor la forma, el contenido y la función de los nuevos movimientos historiográficos del siglo XXI. Partiendo de la base que las tendencias actuales existen, desde mediados de los años 90, en versiones más o menos larvadas y organizadas ${ }^{173}$, y son imprescindibles para asegurar el carácter colectivo (en tiempos de fragmentación), el dinamismo y la adaptación a nuestro tiempo de la disciplina histórica. La experiencia de Romero nos reafirma, pues, en la necesidad hoy de un tipo de corrientes historiográficas más abiertas, reflexivas y globales, sujetas a una dialéctica continua de debate y consenso. De manera que sea posible combinar un mínimo común denominador y un debate permanente ${ }^{174}$, un pensamiento crítico y un pensamiento autocrítico..., trabajando siempre con dos ideas a la vez en la cabeza. Romero lo hacía, como seguidor al tiempo que crítico de sus autores de referencia, como Marx y Maquiavelo. Hoy debería resultarnos más sencillo: por la complejidad de las mentalidades

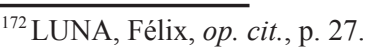

${ }^{173}$ BARROS, Carlos. Últimas tendencias de la historiografía española. 2007. Disponible en: www.hdebate.com/Spanish/presentaciones/lugares/montevideo3/audio.htm; Tendencias generales de la historiografía actual. 2008. Disponible en: www.h-debate.com/Spanish/presentaciones/lugares/ caceres/caceres1.htm.

${ }^{174}$ BARROS, Carlos. Historia a Debate, un paradigma global para la escritura de la historia. Historia a debate. I. Reconstrucción, Santiago, Historia a Debate, 2009, p. 133-137.
} 


\section{Carlos BARROS. José Luis Romero y la Historia del siglo XXI.}

actuales, por las nuevas tecnologías que están democratizando la comunicación social y también académica.

\section{Iniciativa latina}

Dejamos para el último lugar la contribución que mejor resume buena parte de lo dicho: el precoz ejemplo de José Luis Romero como historiador latino de ambición global. Romero "sólo" pudo ser una rareza ${ }^{175}$ en un siglo XX en que la innovación "sólo" podía irradiar de Europa hacia el mundo latino, y no al revés. La globalización en curso ha cambiado radicalmente los datos del problema: se puede y se debe innovar desde las periferias ${ }^{176} \mathrm{y}$ conseguir además una importante proyección internacional. ${ }^{177}$ Los conocimientos historiográficos del siglo XX están ya en gran medida extendidos y asumidos en otros continentes, podemos y debemos buscar con la propia cabeza, autocrítica e internacionalmente, nuevas respuestas a nuevos problemas. Aprovechemos a tal fin que el español es ahora la segunda lengua franca occidental, después del inglés, por delante del francés y otros idiomas europeos, dentro y fuera de Internet, medio nivelador por excelencia de la comunicación historiográfica. Recuperemos, en suma, al avanzado José Luis Romero para la nueva historiografía global del siglo XXI.

Recbido: 30/08/2011 - Aprovado: 09/03/2012

\footnotetext{
${ }^{175}$ Véase la nota 27.

${ }^{176}$ Véase la nota 1.

${ }^{177}$ La experiencia de Historia a Debate es, al respecto, el mejor argumento, véase Primeras conclusiones del III Congreso Internacional Historia a Debate (14-18 de Julio de 2004), op. cit., p. 77-78.
} 